\title{
One Pot Synthesis of PEGylated Bimetallic Gold- Silver Nanoparticles for Imaging and Radiosensitization of Oral Cancers
}

\author{
Shameer Ahmed' \\ Gunjan Baijal $^{2}$ \\ Rudrappa Somashekar $\mathbb{D}^{3}$ \\ Subramania lyer (iD ${ }^{4}$ \\ Vijayashree Nayak (D) \\ 'Department of Biological Sciences, Birla \\ Institute of Technology \& Science, Pilani, \\ K.K. Birla Goa Campus, Sancoale, Goa, \\ India; ${ }^{2}$ Department of Radiation \\ Oncology, Manipal Hospital Goa, Panaji, \\ Goa, India; ${ }^{3}$ Centre for Materials Science \\ and Technology, Vijnana Bhavan, Mysore, \\ Karnataka, India; ${ }^{4}$ Department of Head \\ and Neck Oncology, Amrita Institute of \\ Medical Sciences, Ponekkara, Cochin, \\ India
}

Correspondence: Vijayashree Nayak Department of Biological Sciences, Birla Institute of Technology and Science, Pilani, K.K. Birla Goa Campus, NH I7B, Bypass Road, Zuarinagar, Sancoale, Goa, 403726, India

Tel +9l 8322580101 (Ext. 16I)

Email vijayashree@goa.bits-pilani.ac.in
Background: Radiotherapy is an important treatment modality for many types of head and neck squamous cell carcinomas. Nanomaterials comprised of high atomic number $(Z)$ elements are novel radiosensitizers enhance radiation injury by production of free radicals and subsequent DNA damage. Gold nanoparticles are upcoming as promising radiosensitizers due to their high (Z) biocompatibility, and ease for surface engineering. Bimetallic nanoparticles have shown enhanced anticancer activity compared to monometallic nanoparticles.

Materials and Methods: PEG-coated $\mathrm{Au}-\mathrm{Ag}$ alloy nanoparticles (BNPs) were synthesized using facile one pot synthesis techniques. Size of $\sim 50 \pm 5 \mathrm{~nm}$ measured by dynamic light scattering. Morphology, structural composition and elemental mapping were analyzed by electron microscopy and SAXS (small-angle X-ray scattering). The radiosensitization effects on $\mathrm{KB}$ oral cancer cells were evaluated by irradiation with 6MV X-rays on linear accelerator. Nuclear damage was imaged using confocal microscopy staining cells with Hoechst stain. Computed tomography (CT) contrast enhancement of BNPs was compared to that of the clinically used agent, Omnipaque.

Results: BNPs were synthesized using PEG 600 as reducing and stabilizing agent. The surface charge of well dispersed colloidal BNPs solution was $-5 \mathrm{mV}$. Electron microscopy reveals spherical morphology. HAADF-STEM and elemental mapping studies showed that the constituent metals were $\mathrm{Au}$ and $\mathrm{Ag}$ intermixed nanoalloy. Hydrodynamic diameter was $\sim 50 \pm 5 \mathrm{~nm}$ due to PEG layer and water molecules absorption. SAXS measurement confirmed BNPs size around $35 \mathrm{~nm}$. Raman shift of around $20 \mathrm{~cm}^{-1}$ was observed when BNPs were coated with PEG. ${ }^{1} \mathrm{H}$ NMR showed extended involvement of ${ }^{-} \mathrm{OH}$ in synthesis. BNPs efficiently enter cytoplasm of $\mathrm{KB}$ cells and demonstrated potent in vitro radiosensitization with enhancement ratio $\sim 1.5-1.7$. Imaging Hoechst-stained nuclei demonstrated apoptosis in a dose-dependent manner. BNPs exhibit better CT contrast enhancement ability compared to Omnipaque.

Conclusion: This bimetallic intermix nanoparticles could serve a dual function as radiosensitizer and CT contrast agent against oral cancers, and by extension possibly other cancers as well. Keywords: bimetallic intermix alloy nanoparticles, radiosensitizers, nanomedicine, PEG, poly ethylene glycol, CT contrast, apoptosis

\section{Background}

Oral cancer refers to tumours diagnosed at the site such as lips, 2/3rd anterior region of the tongue, upper and lower alveolar ridges, hard palate, buccal mucosa, retromolar trigone, and sublingual area, including floor of the mouth. ${ }^{1}$ Of oral cancers, around $80-90 \%$ are carcinomas histopathologically differentiated in the squamous layer of mucosal epithelium, also known as oral squamous cell 


\section{Graphical Abstract}

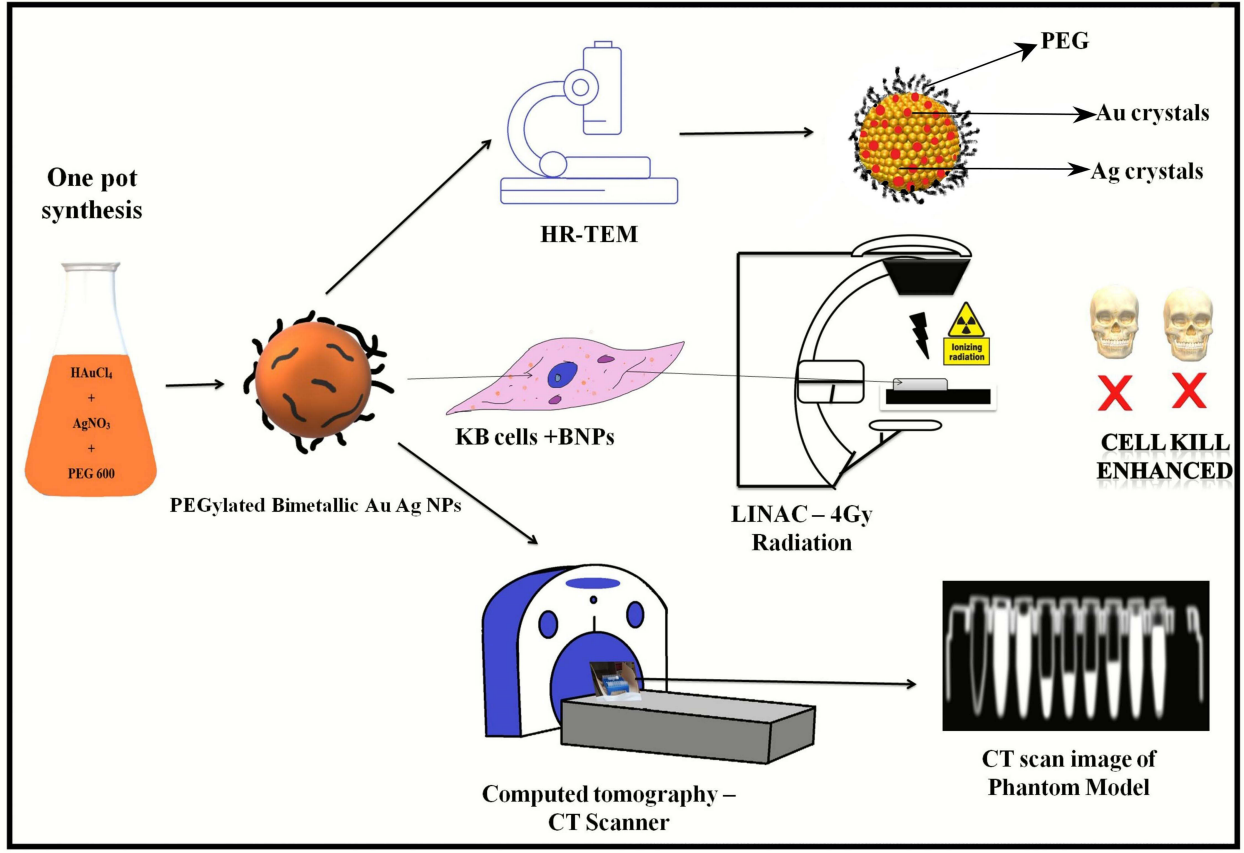

carcinomas (OSCCs). ${ }^{2}$ Radiation therapy (RT) is chosen as a definitive therapy or in some cases postoperatively, as a major modality in the treatment of primary oral cancer. The loss of saliva secretion can have a negative impact. Salivary glands can be protected by barrier methods such as shields or sparing technique using IMRT (intensitymodulated radiation therapy), which have yielded decreased incidence and a degree of xerostomia. ${ }^{3}$ Radiosensitization is the process to improve radiation damage to cancer cells while restricting the radiation effects to adjacent normal tissue; the exploitation of tumour cell cycle, metabolic, and micro-environmental properties using radiosensitizing compounds can selectively enhance damage to cancerous cells. ${ }^{4}$ Heavy-metal nanoparticles which have high atomic number $(Z)$ values are promising agents as radiosensitizers because they can scatter, absorb, and emit radiation energy. The synthesis of these is a robust process by which a desired size and shape can be achieved. They also have the following advantages such as low cytotoxicity, good biocompatibility, and surface functionalization via bioengineering. ${ }^{5}$ Gold nanomaterials showed good effects in various tumours with satisfying criteria. ${ }^{6}$ Other high $\mathrm{Z}$ nanomaterials have also been tested as radiosensitizers such as silver and hafnium oxide nanoparticles. $^{7-9}$ Size of nanoparticles plays a crucial role such as increased penetration and retention behaviour. In enhancing radiosensitization effect to cancer cell-making, 50nm metallic nanoparticles of gold, silver and hafnium oxide nanoparticles perform better than other sizes. ${ }^{10-13}$ Bimetallic colloids intrigue researchers due to their interesting structure and their unique catalytic, electronic and optical properties. ${ }^{14}$ The bimetallic NPs based on structure are categorized as: (i) core-shell alloy, (ii) cluster in the cluster, and (iii) random alloy and alloy structures. The size and shape of bimetallic NPs are specifically dependent on their synthesis technique and fabrication conditions. ${ }^{15}$ Radiosensitization plays an important role in the management of most cancers and is considered "the new dogma in cancer treatment". ${ }^{72}$ In pre-clinical studies gold nanoparticles (AuNPs) are proved as a promising candidate as a radiosensitizers agent. ${ }^{16}$ A study done on $\mathrm{KB}$ cell line using gold nanoparticles functionalized with thiol PEG of various shapes while maintained at a size around $50 \mathrm{~nm}$ found that spherical shape $\mathrm{Au}$ NPs internalize the cancer cells better than spike- and rod-shaped gold nanoparticles. Also, the SER (sensitization enhancement ratio) of spherical Au NPs was around 1.62 higher among the three NPs. ${ }^{74}$ Recent studies 
have shown bimetallic NPs out-perform as a better radiosensitizer than counterpart monometallic NPs; a 2-fold enhanced radiation-induced cell kill was seen when exposed to $\mathrm{ZnO} / \mathrm{SiO}_{2}$ NPs in comparison to cells exposed only to radiation $(2-10 \mathrm{~Gy}, 200 \mathrm{kVp}) .{ }^{17} \mathrm{Au}$ bound titanium showed a radiosensitization enhancement of $\sim 1.8$ and $\sim 1.2$ when particles were fabricated onto dimension 10-30 nm and 5-10 nm supports. ${ }^{18}$ The mechanism of AuNPs radiosensitization is that it enhances radiation effects by means biological and physical interactions with IR (ionizing radiation). In the physical phase of interactions, AuNPs exert cellular damage by increasing the production of photoelectrons, Auger electrons and low energy secondary electrons. In the chemical phase, the surface of AuNPs, which is electronically active, leads to catalyzation and the formation of radicals including reactive oxygen species (ROS), and the very low energy electrons chemically sensitize the nuclear components and DNA to IR-induced damage. Lastly, in the biological phase, gold NPs enhance the effects of IR via DNA repair inhibition, cell cycle disruption, and oxidative stress. ${ }^{19}$ Cancer radiosensitization is the event that depends on factors like internalization of NPs in cancer cells, the process influenced directly by particle size and its surface chemistry. ${ }^{20}$ Previous studies have shown that alloy of gold silver bimetallic nanoparticles have enhanced anticancer activity also, the mechanism and path of bimetallic cytotoxicity is activation of caspase and the p53/Bax/Bcl-2 apoptotic pathway against various cancer cell lines. ${ }^{21-24}$ PEG (poly [ethylene glycol]) is cost-effective, widely used in pharmaceutical avenue due to its excellent watersolubility, low toxicity and being eco-friendly polymers that is Food and Drug Administration (FDA) and European Medicines Agency (EMA) approved ${ }^{25}$ for various applications. Recently it is used for the fabrication of metallic NPs due to its interactions with metallic NPs through both electrostatic and steric effects. ${ }^{26,27}$ NPs whose surface is modified or functionalized with PEG has the advantage of prolonged circulation time in the blood stream and reaches the target site. ${ }^{28}$ Surface functionalized NPs improve the quality of radiosensitizer and combat molecular blockade of cell death. Histidineanchored gold nanoclusters (Au NCs-His) showed as a radiosensitizer with a high sensitization enhancement ratio of $\sim 1.54$. The mechanism is $\mathrm{Au}$ NCs-His can decrease the intracellular GSH level and enhance reactive oxygen species (ROS) production intracellular. ${ }^{75}$ Another study using both in vitro and in vivo models showed gold nanospikes (GNSs) functionalized with thiol PEG and peptide molecule TAT has shown very high SER of about 2.30; the underlying mechanism for such SER was increased (ROS), mitochondrial depolarization, and cell cycle redistribution. ${ }^{76}$ Also, the efficiency and efficacy of the metal-based nanoformulation depends upon the source and type such as X-rays or gamma rays, and also energy of the radiation, quantity and location of nanomaterial within the tissue. Active targeting by coating of ligands or antibodies and localization along with pharmacokinetic profile of the NPs will generate more efficient therapy with less adverse effects to surrounding healthy tissue. ${ }^{29,30}$ In recent years, gold-silver nanoalloy or $\mathrm{Au}-\mathrm{Ag}$ bimetallic nanoparticles gained special attention because of their unique properties such as anticancer agent, radiosensitizers and contrast agent for imaging in comparison with individual monometallic systems. ${ }^{31-35}$

To explore the advantageous and synergistic property of an alloy, this is first of such studies, we report here one pot synthesis of colloidal PEGylated bimetallic $\mathrm{Au}-\mathrm{Ag}$ nanoparticles using PEG 600 by polyol method reducing $\mathrm{HAuCl}_{4}$ and $\mathrm{AgNO}_{3}$ simultaneously. These nanoparticles were characterized thoroughly to establish the structure and nano architect and showed anticancer activity, nuclear damage, and potential radiosensitizer against oral cancer cell line. A phantom model demonstrated CT nanocontrast agents because of the presence of gold when compared to an omnipaque-iodine-based CT contrast agent.

\section{Materials and Methods}

\section{Materials}

Gold (III) chloride trihydrate $\left(\mathrm{HAuCl}_{4} \cdot 3 \mathrm{H}_{2} \mathrm{O}, 99.9 \%\right)$ and silver nitrate $\left(\mathrm{AgNO}_{3}, 99.9 \%\right)$ as precursors, Poly ethylene glycol $\{\mathrm{PEG}\}\left(\mathrm{HO}-\left[\mathrm{CH}_{2}-\mathrm{CH}_{2}-\mathrm{O}\right]_{n}-\mathrm{H}\right)$ with molecular weight 600 (bio ultra, PEG 600) were used as both reducing and stabilizing agents. Sodium hydroxide pellets were purchased from Fisher Scientific and were dissolved in water and used to alter the $\mathrm{pH}$. Milli $\mathrm{Q}$ water was used (purity up to $18.2 \mathrm{M} \Omega \mathrm{cm}^{-1}$ Elga Option Q7). Dulbecco's Modified Eagle Medium (DMEM), fetal bovine serum (FBS), phosphate buffer saline (PBS), antibiotic antimycotic solution, Gentamicin solution and trypsin-EDTA solution were purchased from Himedia Laboratories (Mumbai, India). Used in the following research were: 2'-(4-hydroxyphenyl)-5-(4-methyl-1-piperazinyl)-2,5'-bi

-1H-benzimidazoletrihydrochloride (Hoechst 33258) hydrate, 3-(4, 5-dimethylthiazol-2-yl)-2, 5-diphenyl 
tetrazolium bromide (MTT), and deuterium. ${ }^{77} \mathrm{~KB}$ cell line was purchased from National Centre for Cell Science (NCCS), Pune, India. Chemicals used in the experiments were of molecular and analytical grade. Unless specified, all reagents were used without further purification.

\section{Synthesis of PEGylated Bimetallic Au-Ag NPs (BNPs)}

BNPs with an average hydrodynamic size of $50 \pm 5 \mathrm{~nm}$ using PEG 600 were synthesized. $1 \%$ sodium hydroxide $\mathrm{NaOH}(350 \mu \mathrm{L})$ was added to a mixture of PEG $600(500$ $\mu \mathrm{L})$ and water $(50 \mathrm{~mL})$ taken in an Erlenmeyer flask. To this, a mixture of $\mathrm{AgNO}_{3}(1 \mathrm{mM}, 3.5 \mathrm{~mL})$ and $\mathrm{HAuCl}_{4}$ $(1 \mathrm{mM}, 3.5 \mathrm{~mL})$ was added and boiled for 10 minutes on a hot plate around $140^{\circ}-180^{\circ} \mathrm{C}$. The heating plate was turned off and the flask was left on heating plate for another 5 mins as hold time for gradual cooling. The change of colour in flask to orange indicates the formation of PEG reduced and stabilized bimetallic gold-silver nanoparticles. The $\mathrm{pH}$ was measured, and the synthesis was done in triplicates. Excess PEG and unreacted agents were removed from the colloidal solution by centrifuging the particles at $12,000 \mathrm{rpm}$ for 30 minutes, removing the supernatant, and resuspending the BNPs in the Milli Q. Washing was performed twice. BNPs were stable colloids for more than 1.5 years post-synthesis. The $\mathrm{pH}$ measured was around $\sim 7.2$.

\section{Characterization of PEGylated Bimetallic $\mathrm{Au}-\mathrm{Ag}$ NPs (BNPs)}

Dynamic light scattering (DLS) was used to measure the hydrodynamic size of BNPs. Particle size and zeta potential analysis were done using Microtrac Nanotrac Wave (USA). Hydrodynamic diameter of colloidal particles and conjugates at the surface can be evaluated by DLS. Transmission electron microscopy (TEM), high resolution, transmission electron microscopy (HR-TEM), selected area electron diffraction (SAED), high-angle annular dark field (HAADF) and elemental mapping, that is, shape, morphology, size and also the diffraction pattern of the PEG reduced, and capped nanoparticles, were studied using a Transmission Electron Microscope (Titan Themis 300kV from FEI, now Thermo) operating at $200 \mathrm{kV}$. A laboratory-based small-angle X-ray scattering (SAXS) facility was used to study the nanoparticles. The concentration of BNPs was determined by using Inductively Couple Plasma Mass Spectrometry (ICP-MS) Agilent ICPMS 7900 with (UHMI) Ultra High Matrix Introduction. The
UV-Vis spectra of the synthesized BNPs were recorded on a UV-Vis spectrometer (Multiskan ${ }^{\mathrm{TM}}$ GO Micro plate Spectrophotometer, Thermo Fisher Scientific), using standard well plate at room temperature, over a spectral range between $200 \mathrm{~nm}$ to $900 \mathrm{~nm}$ at a spectral resolution of $2 \mathrm{~nm}$. The Raman spectroscopy experiments have been performed on an XPLORA PLUS spectrometer (Horiba Scientific, France). The Raman spectra have been recorded using an excitation wavelength of $532 \mathrm{~nm}$ (diode laser) at room temperature. The resolution of the spectra was $2 \mathrm{~cm}-1$. All the NMR spectra were recorded by Agilent 400-MR DDR2 (Varian, Palo Alto, USA) spectrometer and the solvent used was DMSO for calibration. Chemical shifts are valued in ppm.

\section{In vitro Cytotoxicity and Cell Viability Evaluation of BNPs}

In terms of cell culture, $\mathrm{KB}$ cells (derived from an epidermal carcinoma of the mouth) were maintained in Dulbecco's modified Eagle medium supplemented with 10\% FBS and $1 \%$ streptomycin- gentamicin antibiotics (Himedia) at $37^{\circ} \mathrm{C}$ in a humidified incubator containing $5 \% \mathrm{CO}_{2}$, which was maintained at the exponential growth state. Cells were passaged using $0.25 \%$ trypsin. Approximately, $1 \times 10^{4} \mathrm{~KB}$ cells/ wells were cultured in a 96-well plate. After $24 \mathrm{~h}$, the culture medium was removed and fresh medium containing BNPs between 0 and $0.34 \mu \mathrm{g} / \mathrm{mL}$ were added to the test wells and the cells were placed in the incubator for an additional 24 h. Each concentration was tested in triplicate. Also, experiment was done at three different time points. Cells without nanoparticles were used as control. At the end of the incubation period, media was removed and MTT assay was performed: $50 \mu \mathrm{L}$ of MTT solution $(5 \mathrm{mg} / \mathrm{mL})$ was added to each well and incubated for $3 \mathrm{hrs}$. Then, excess MTT was excluded and $100 \mu \mathrm{L}$ DMSO was added to dissolve formazan crystals. Absorbance was measured at 570nm in Multiskan ${ }^{\mathrm{TM}}$ GO Microplate reader (Thermo scientific, USA); all the cytotoxicity methodology and procedure were done. ${ }^{77}$

\section{Radiation Therapy and Radiosensitization - in vitro (PEGylated Bimetallic Au-Ag NPs [BNPs])}

Approximately $1 \times 10^{4} \mathrm{~KB}$ cells/well were cultured in various 96-well plates. After $24 \mathrm{~h}$, the culture medium was removed and fresh media was added, following which the 96-well plates were labelled. The cells were irradiated by $6 \mathrm{MV}$ photon X-rays using a Versa $\mathrm{HD}^{\circledR}$ (Elekta, Crawley, England) linear accelerator equipped with Agility ${ }^{\circledR}$ collimator system), as 
supporting information Figure S3 shows Photograph of LINAC device used for this research, located in Manipal Hospital, Dona Paula, Goa. Source-to-surface distance (SSD) of $100 \mathrm{~cm}$ and field size of $20 \times 20 \mathrm{~cm}^{2}$ and delivered total doses of 2, 4, 6 and 8 Gy to various 96-well plates with a dose rate of $200 \mathrm{MU} \mathrm{min}^{-1}$. Following irradiation, MTT assay was performed, and cell viability was calculated. To test the radiosensitization capacity of BNPs, KB cells were cultured in 96well plates at a density of $1 \times 10^{4}$ cells/well for $24 \mathrm{~h}$. After $24 \mathrm{~h}$, the culture medium was removed and fresh medium containing between 0 and $0.34 \mu \mathrm{g} / \mathrm{mL}$ BNPs were added to the test wells and the cells were placed in the incubator for an additional $24 \mathrm{~h}$. After this, the media was replaced with fresh media washing away the BNPs which did not internalize the $\mathrm{KB}$ cells. The KB cells with internalized BNPs were irradiated at 4Gy X-rays, and then incubated for $24 \mathrm{~h}$. Finally, cell viability was examined using a MTT assay. Each concentration was tested in triplicate. Also, the experiment was done at three different time points.

\section{Assessment of Nuclear Damage by Hoechst 33258}

Radiation-induced nuclear damage such as apoptosis, mitotic catastrophe, and cellular senescence is well documented using 4, 6-diamidino-2-phenylindole (DAPI) staining and fluorescent microscopy and the following experiment is done with few modifications. ${ }^{36}$ Briefly, KB cells were plated in 6-well plates along with cover slip $3 \times 10^{5}$ cells per well and incubated at $37^{\circ} \mathrm{C}$ and $5 \% \mathrm{CO}_{2}$ for $24 \mathrm{~h}$, following which fresh media was applied along with $0.34 \mu \mathrm{g} / \mathrm{mL}$ of BNPs, $\mathrm{H}_{2} \mathrm{O}_{2}$ was used as a positive control and only culture media was control and incubated at $37^{\circ} \mathrm{C}$ and $5 \% \mathrm{CO}_{2}$ for 24 h. Replacing all with fresh media, the cells were irradiated with 4Gy X-rays and incubated for $24 \mathrm{~h}$. Following incubation, cells were fixed with fixation solution 3\% paraformaldehyde $+2 \%$ sucrose, washed twice with PBS (1X). Then cells on cover slip were counterstained with Hoechst 33258 in 1:5000 dilutions in PBS. The stained cover slips were inverted on slides and then mounted using adherent, following which they were viewed under a fluorescent microscope (Olympus Corporation FV3000).

\section{FBS Stability Assay: PEGylated Bimetallic $\mathrm{Au}-\mathrm{Ag}$ NPs (BNPs)}

The stability of BNPs was evaluated by calculating the change in turbidity in FBS. $150 \mu \mathrm{L}$ of BNPs suspension $(0.34 \mu \mathrm{g} / \mathrm{mL})$ was added to $150 \mu \mathrm{L}$ of FBS in 96-well plates and incubated for different time points up to 72 $\mathrm{h}$ at $37{ }^{\circ} \mathrm{C}$ in an incubator. After this, the absorbance of each sample was measured at $415 \mathrm{~nm}$. 5\% glucose solution was employed as a negative control. ${ }^{37}$

\section{Computed Tomography Scan of Phantom Model}

Regarding CT imaging and HU measurements, a phantom model was made using $1.5 \mathrm{~mL}$ centrifuge tubes and filled with $0.6 \mathrm{mg} / \mathrm{mL}$ of BNPs in Milli Q, 1x PBS, Milli Q as control and clinically used Novaplus Omnipaque, CT contrast agent of 2 concentration $5 \mathrm{mg} / \mathrm{mL}$ and $10 \mathrm{mg} / \mathrm{mL}$. CT data was acquired using Philips Ingenuity (PI) 64-slice MDCT scanner (Philips Medical Systems, Massachusetts, USA). In supporting information, Figure S4 shows a photograph of the CT instrument used to image the phantom. Imaging parameters were as follows: effective pixel size $=1.0 \mathrm{~mm} ; 120 \mathrm{kVp}, 399 \mathrm{~mA}$; field of view $(\mathrm{FOV})=170 \mathrm{~mm} \times 190 \mathrm{~mm}$; rotation steps $=$ 180; exposure time $=150 \mathrm{~ms} /$ rotation. The images of phantom CT analysis were analyzed with Weasis v1.2.8 software. Calculation of values was done by recording the Hounsfield units (HUs) from randomly selected regions of interest.

\section{Statistical Data Analysis}

Data regarding cell viability were entered into Microsoft Excel and analyzed using IBM SPSS (Statistical Package for the Social Sciences) Statistics for Windows, Version 20 (IBM Corp., Armonk, N.Y., USA). Data was analyzed for normality using the Kolmogorov-Smirnov test. Descriptive statistics were determined. Cell viability was determined while using BNPs, BNPs+4Gy and X-ray dose under various concentrations. Percentage of apoptosis and mitotic catastrophe were analyzed across BNPs, 4Gy, BNPs+4Gy, $\mathrm{H}_{2} \mathrm{O}_{2}, \mathrm{H}_{2} \mathrm{O}_{2}+4 \mathrm{~Gy}$ and control groups. The viability of cell death (\%), percentage of apoptosis and mitotic catastrophe were analyzed across various concentrations using Kruskal-Wallis $\mathrm{H}$ statistic test followed by multiple comparisons with Dunn-Bonferroni post hoc test $(\alpha=0.05)$. The level of statistical significance was determined at $\mathrm{p}<0.05$. All measurements were carried out in triplicate and presented as the mean \pm standard deviation (SD).

\section{Results and Discussion}

\section{Synthesis of PEGylated Bimetallic $\mathrm{Au}-\mathrm{Ag}$ NPs (BNPs)}

The synthesis of PEGylated bimetallic $\mathrm{Au}-\mathrm{Ag}$ NPs is schematically described in Figure 1. The procedure to synthesize NPs was kept simple and one pot methodology was used. It 
is a typical polyol reaction where metal precursors are reduced and stabilized by poly ethylene glycol. The synthesis of BNPs $(\mathrm{Au}-\mathrm{Ag})$ is a chemical reaction in which reduction of both silver and gold precursors takes place simultaneously at elevated temperatures $\left(160^{\circ}-180^{\circ} \mathrm{C}\right)$ and in moderation of $\mathrm{pH}$ using $1 \% \mathrm{NaOH}$. The PEG coated or wrapped BNPs have steric repulsion that prevents them from agglomeration. The presence of the ${ }^{-} \mathrm{OH}$ group shifts the $\mathrm{pH}$ towards alkaline environments, promoting fast reduction of $\mathrm{Au}^{3+}$ and $\mathrm{Ag}^{+}$ions to $\mathrm{Au}^{0}$ and $\mathrm{Ag}^{0}$, respectively; $\mathrm{pH}$ change has the ability to alter dimensional parameters such as size and shape of nanoparticles being formed. ${ }^{38}$ The solution with higher $\mathrm{pH}$ accelerates decomposition of $\mathrm{AuCl}_{3}$ and consequently reduction of gold ions by PEG. The mechanism by which this occurs is due to oxidation of hydroxyl end groups to aldehyde groups and same in silver precursor forming PEGylated Ag NPs. In the absence of $\mathrm{NaOH}$ it is impossible for the reaction to go in a forward direction. ${ }^{39,73}$ From polygonal $\mathrm{Au}$ particles a small amount $\mathrm{Au}^{3+}$ are released during heating from ambient temperature to high temperature of $150^{\circ} \mathrm{C}$ for $10 \mathrm{~min}$; while maintaining this temperature for $10 \mathrm{~min}$ leads to dissolution of surfaces of $\mathrm{Au}$ particles in the presence of $\mathrm{H}^{+}$and $\mathrm{NO}_{3}^{-}$ions. In the presence of $\mathrm{PEG}, \mathrm{Ag}^{+}$ions are reduced and $\mathrm{H}^{+}$ions are formed.

$$
\begin{gathered}
\mathrm{CH}_{2} \mathrm{OH}-\mathrm{CH}_{2} \mathrm{OH} \rightarrow \mathrm{CH}_{3} \mathrm{CHO}+\mathrm{H}_{2} \mathrm{O} \\
2 \mathrm{CH}_{3} \mathrm{CHO}+2 \mathrm{Ag}^{+} \rightarrow 2 \mathrm{Ag}^{0}+2 \mathrm{H}^{+}+2 \mathrm{CH}_{3} \mathrm{COOH}
\end{gathered}
$$

Also, $\mathrm{NO}_{3}{ }^{-}$ions are formed by electrolytic dissociation of $\mathrm{AgNO}_{3}$. The $\mathrm{Au}^{3+}$ and $\mathrm{Ag}^{+}$ions were reduced simultaneously, forming uniform $\mathrm{Au}-\mathrm{Ag}$ nanoalloy intermix NPs. It is shown that some spherical Au particles or excentre
$\mathrm{Au} @ \mathrm{Ag}$ particles are attached to surfaces of silver-rich $\mathrm{Ag} / \mathrm{Au}$ alloy nanowires to reduce the total surface energy (Ostwald ripening). Therefore, they fuse more easily. Other possible reasons could be that some amounts of $\mathrm{Au}$ particles are dissolved by etching and that $\mathrm{Au}^{3+}$ ions are produced from the surfaces of Au particles. Standard cell potential of the following reaction is positive. Lastly, the dissolution reaction of $\mathrm{Ag}(\mathrm{s})$ proceeds spontaneously at the vicinity part if $\mathrm{Au}^{3+}$ cations are released.

$$
\mathrm{Au}^{3+}+2 \mathrm{Ag}(\mathrm{s})-\rightarrow 2 \mathrm{Ag}^{+}+\mathrm{Au}^{+} E^{\circ} \text { cell } 1 / 40.60 \mathrm{eV}
$$

When $\mathrm{Au}-\mathrm{Ag} / \mathrm{Au}$ particles grows to a critical size ( $400 \mathrm{~nm})$, they are stable for thermal annealing and monodispersed $\mathrm{Au}-\mathrm{Ag} / \mathrm{Au}$ particles are the end product. ${ }^{40}$

\section{UV-Visible Spectroscopy of Colloidal BNPs}

UV-vis absorbance spectrum of BNPs shows that the surface plasmon resonance (SPR) band is between the fingerprint region of $\mathrm{Au}$ and $\mathrm{Ag}$ nanoparticles. The optical properties of the BNPs exhibited a plasmon resonance at $479 \mathrm{~nm}$, which suggests that nanoparticles are likely to be intermix alloy $\mathrm{Au}-\mathrm{Ag}$ characteristic in nature. Figure $2 \mathrm{~A}$ shows the absorbance spectrum of colloidal BNPs. The peak maximum seen as a single peak for BNPs implies a homogeneous colloidal intermixture of the $\mathrm{Au}$ and $\mathrm{Ag}$ nanoparticles without formation of individual particles of gold or silver. Figure 2B is a digital photograph of colloidal BNPs which is brownish-orange in colour. ${ }^{35}$ In supporting information, Figure S1, we have shown repeatability of synthesis of BNPs at three different time points using UV-visible spectra. The PEG is a stabilizing

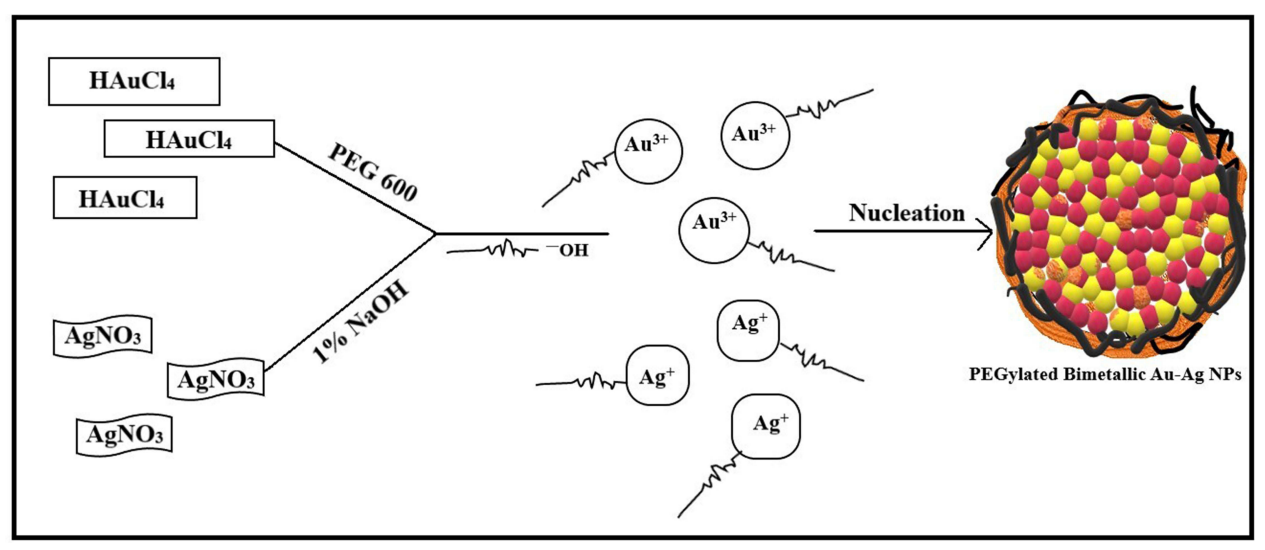

Figure I A schematic representation of Bimetallic Au-Ag nanoparticle synthesis in a PEG 600 solution. The metal ions bind to the reducing metabolites/stabilizing agents and are reduced to metal atoms simultaneously. At optimal pH, metal ions and metabolites interact with similar complexes, forming a small two-metal nanoparticle. Next, at nucleation, they grow and coalescence to form intermixed gold-silver clusters. The reaction proceeds till the particles reach a stable size and shape. 


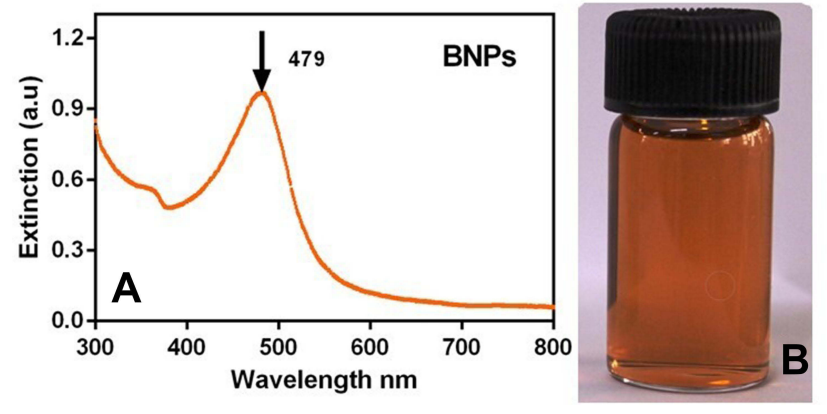

Figure 2 (A) UV-visible spectrum of PEGylated bimetallic Au-Ag NPs (BNPs) and (B) picture of synthesized BNPs (orange-brown in appearance).

agent, which effectively prevented the agglomeration of the freshly formed nanoparticles. Size of the synthesized nanoparticles can be determined by the SPR band. The frequency and width of SPR depends on the shape and size of the nanoparticles, surrounding medium and lastly the dielectric constant of the metal. ${ }^{41}$

\section{Size and Zeta Potential of BNPs with Dynamic Light Scattering Method}

Figure 3A shows particle size distribution (PSD) of BNPs measured using dynamic light scattering (DLS). BNPs showed a mean hydrodynamic diameter of $50 \pm 5 \mathrm{~nm}$. BNPs were retained as monodispersed colloid in Milli $\mathrm{Q}$ with hydrodynamic diameter of $50 \mathrm{~nm}$. The size of BNPs were also measured from the TEM images using ImageJ software, and the measurements are comparable to measurements obtained from DLS. The difference in $D_{\text {hydro }}$ and $D_{\text {TEM }}$ (the size of the dried particles obtained by TEM) was due to the binding and capping of PEG 600 to the nanoparticle surface; $\mathrm{D}_{\text {hydro }}-D_{\mathrm{TEM}}$ is the corona, which is around $15 \mathrm{~nm}$. As shown in Figure $3 \mathrm{~B}$, the electrophoretic mobility measurements for the BNPs was recorded by zeta potential values obtained by Zetasizer. The particle $\zeta$-potential ranged from $-5.6 \mathrm{mV}$ in Milli Q water. Low negative surface charge was likely caused by the presence of absorbed water molecules as PEG is hydrophilic in nature. The negative zeta potentials indicate negatively charged surface ligand on the colloidal BNPs. The stability of the dispersed nanoparticles depends on their $\mathrm{pH}$ and the surface charge. ${ }^{42}$ PEG chains on the particle surface have stabilized well by virtue of strong steric repulsion, which is in contrast to electrostatic repulsion, which is generally insensitive to different ions in the vicinity. $^{43}$

\section{TEM Images (Morphology and Size Analysis) of BNPs}

Figure 4A and B shows TEM image and particle size distribution histograms of the BNPs, respectively. All the nanoparticles are near spherical and well dispersed. The size distribution analysis based on the TEM images yields a mean of approximately $36 \pm 5 \mathrm{~nm}$. The TEM confirmed the bimetallic structures of BNPs between silver and gold due to the contrast difference caused by the atomic number $\mathrm{Z}$ of silver and gold (47 for Ag; 79 for $\mathrm{Au}$ ), respectively. ${ }^{44}$

\section{Small-Angle X-Ray Scattering (SAXS) and Small-Angle Neutron Scattering (SANS) Study of BNPs}

The scattering intensity was recorded as a function of scattering wave vector transfer $Q(=4 \pi \sin \theta / \lambda$, where $2 \theta$ is the scattering angle and $\lambda$ is the wavelength of $\mathrm{X}$-ray). The $Q$-range of the instrument was $0.1-2.3 \mathrm{~nm}^{-1}$. In the case of $\mathrm{X}$-rays, as shown in Figure 5, the scattering is mostly from
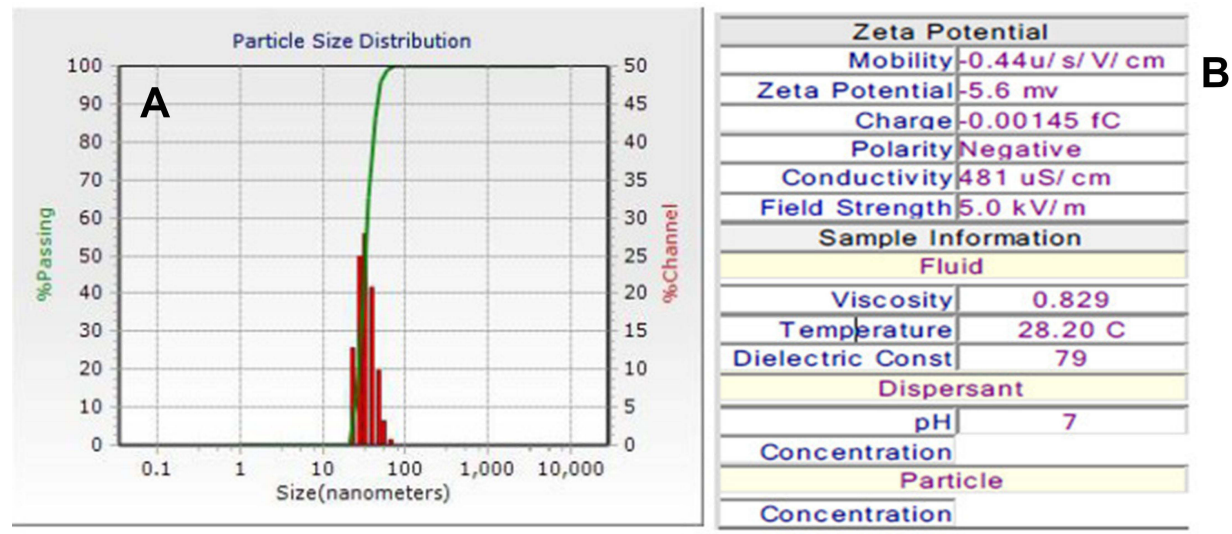

Figure 3 (A) The hydrodynamic diameters $\left(D_{\text {hydro }}\right)$ of BNP $50 \pm 5 \mathrm{~nm}$ in Milli Q water $(\mathrm{pH} \sim 7.4$ manually measured) (B) Zeta potential $-5.6 \mathrm{mV}$ and mobility. 

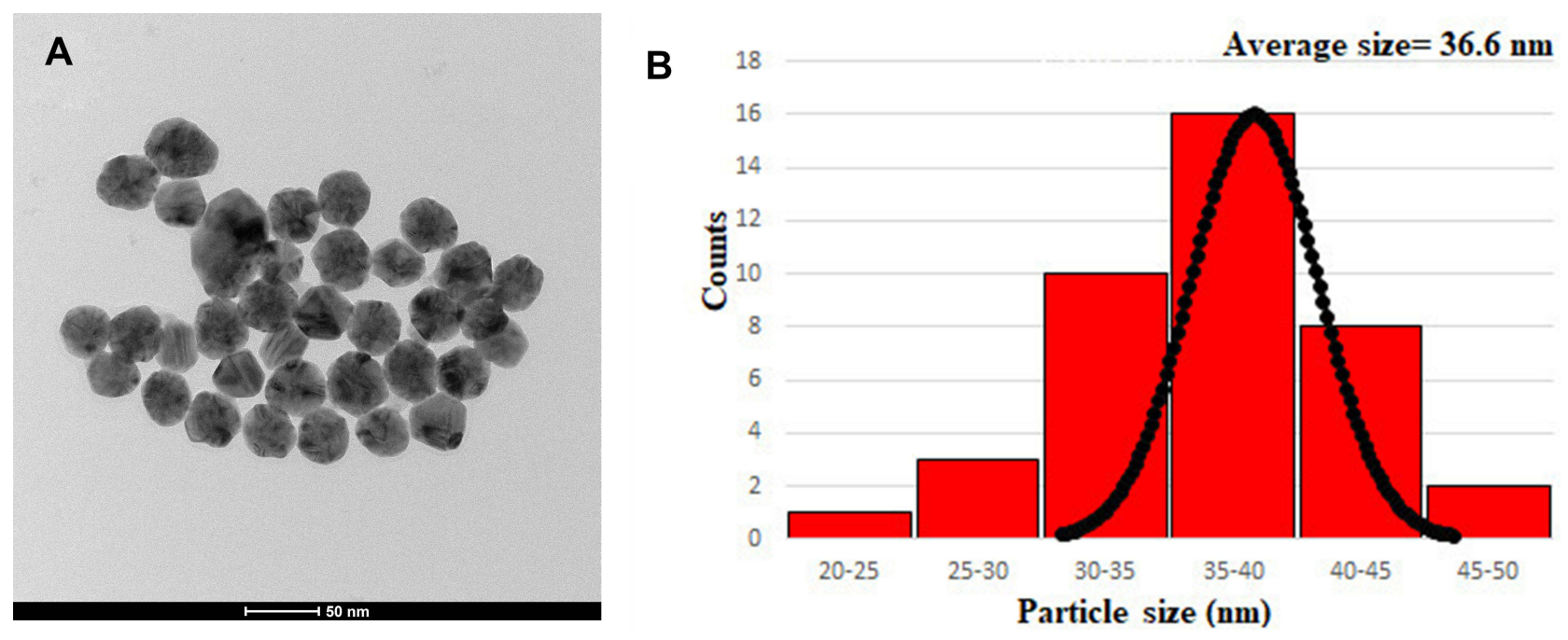

Figure 4 (A) TEM image of BNPs and (B) Histogram showing particle size distribution of BNPs.

the bimetallic part (high $\mathrm{Z}$ component) as compared to polymer (low $\mathrm{Z}$ component). The data are fitted with the diameter of BNPs equal to $35.2 \mathrm{~nm}$. The SANS working parameters along with SANS analysis of BNPs including calculation and spectrum are shown in supporting information (Figure S2 provides insight into this experiment).

\section{High-Resolution Electron Microscopy (HRTEM) and SAED Pattern for Crystal Structure Analysis of BNPs}

Figure 6A shows the HRTEM images of the PEGylated bimetallic $\mathrm{Au}-\mathrm{Ag}$ NPs. An appreciable difference in the contrast between the lighter and darker regions implies the formation of the bimetallic Au-Ag NPs. Also, multiple lattice fringes with an interplanar spacing $0.20 \mathrm{~nm}$, which was indexed to the (200) plane of face-centred cubic (FCC) of silver, whereas the measured lattice spacing of $0.23 \mathrm{~nm}$ matched well with the (111) planes of FCC gold. ${ }^{45,46}$ Powder XRD is a robust tool for characterization of crystal structure of nanomaterials. Based on the position of $2 \theta$ values of corresponding metals, it is easy to figure out the structure (alloy, core/shell or physical mixture) and crystallinity of the prepared nanoparticles. This method was particularly difficult to be applied to the structure and characterization of the present BNPs because the crystalline lattice constants of $\mathrm{Ag}$ and $\mathrm{Au}$ are very similar to each other (4.086 $\AA$ for $\mathrm{Ag} ; 4.078 \AA$ for $\mathrm{Au}$ ). Also, the presence of PEG polymer showed amorphous peaks. Hence, the SAED pattern was recorded and shown in Figure 6B.The SAED pattern indicates that the BNPs are nanocrystals with growth

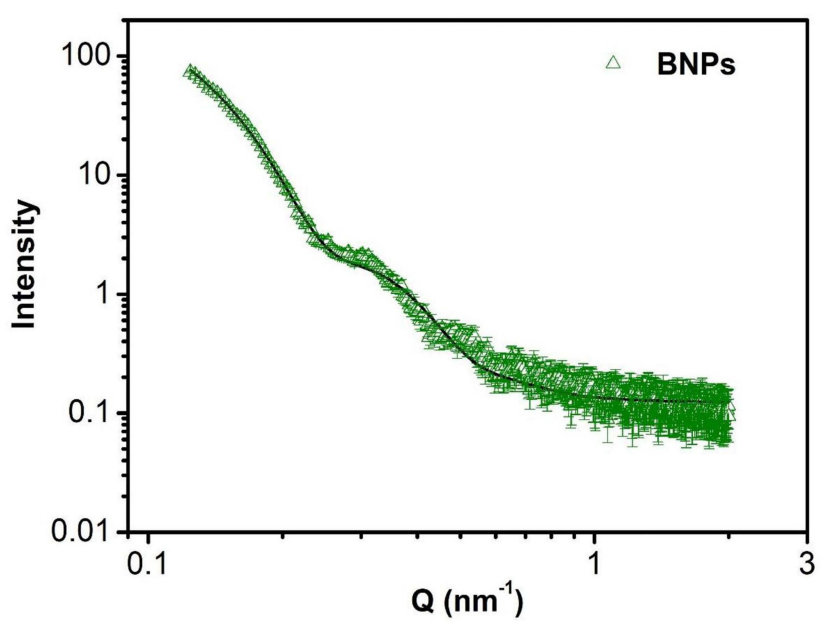

Figure 5 SAXS data of PEGylated bimetallic Au-Ag NPs (BNPs). The solid curves are theoretical fits to the experimental data.

along the dimension of (111), (200), (220) and (311) crystal planes with corresponding $2 \theta .^{47}$

\section{High-Angle Annular Dark-Field Scanning Transmission Electron Microscopy (HAADF- STEM) Analysis of BNPs}

In Figure 7C, the HAADF image of BNPs shows a contrast between $\mathrm{Au}$ and $\mathrm{Ag}$ elements; the contrast is by virtue of Rutherford scattering. Signal in HAADF-STEM mode depends on the atomic number $(Z)$ of the elements, low brightness refers to the Ag (lighter element), while the strong brightness corresponds to the $\mathrm{Au}$ (heavy element). ${ }^{48}$ The image clearly shows the intermix distribution of the $\mathrm{Ag}$ and $\mathrm{Au}$ elements in the BNPs. The EDS elemental mapping 


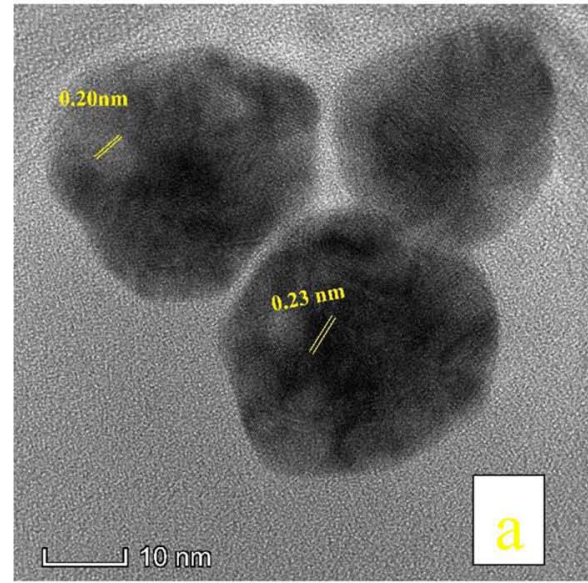

A

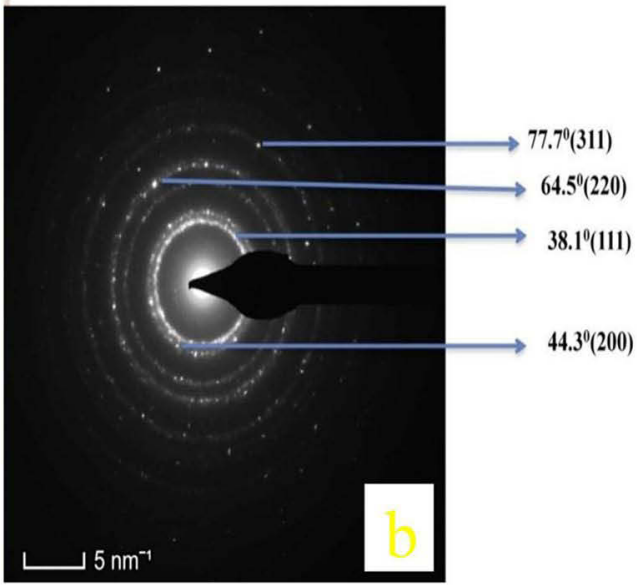

B

Figure 6 (A) HRTEM image of PEGylated bimetallic Au-Ag NPs, together with lattice spacing of Au-Ag NPs nanocrystal. (B) SAED patterns of PEGylated bimetallic Au-Ag NP

analysis in HAADF-STEM in Figure 7D and E confirms their structure: $\mathrm{Ag}$ and $\mathrm{Au}$ chemical composition in the presence of Au signals (red) and Ag signals (blue) in the bimetallic nanoparticles was indicated. The HAADF image and EDX mapping in Figure 7F shows the coexistence of nano alloyed $\mathrm{Ag}$ and $\mathrm{Au}$ within the nanoparticles in BNPs. Also, EDX spectrum and mapping of elements for a pool of particles is taken as a significant example on the BNPs. It
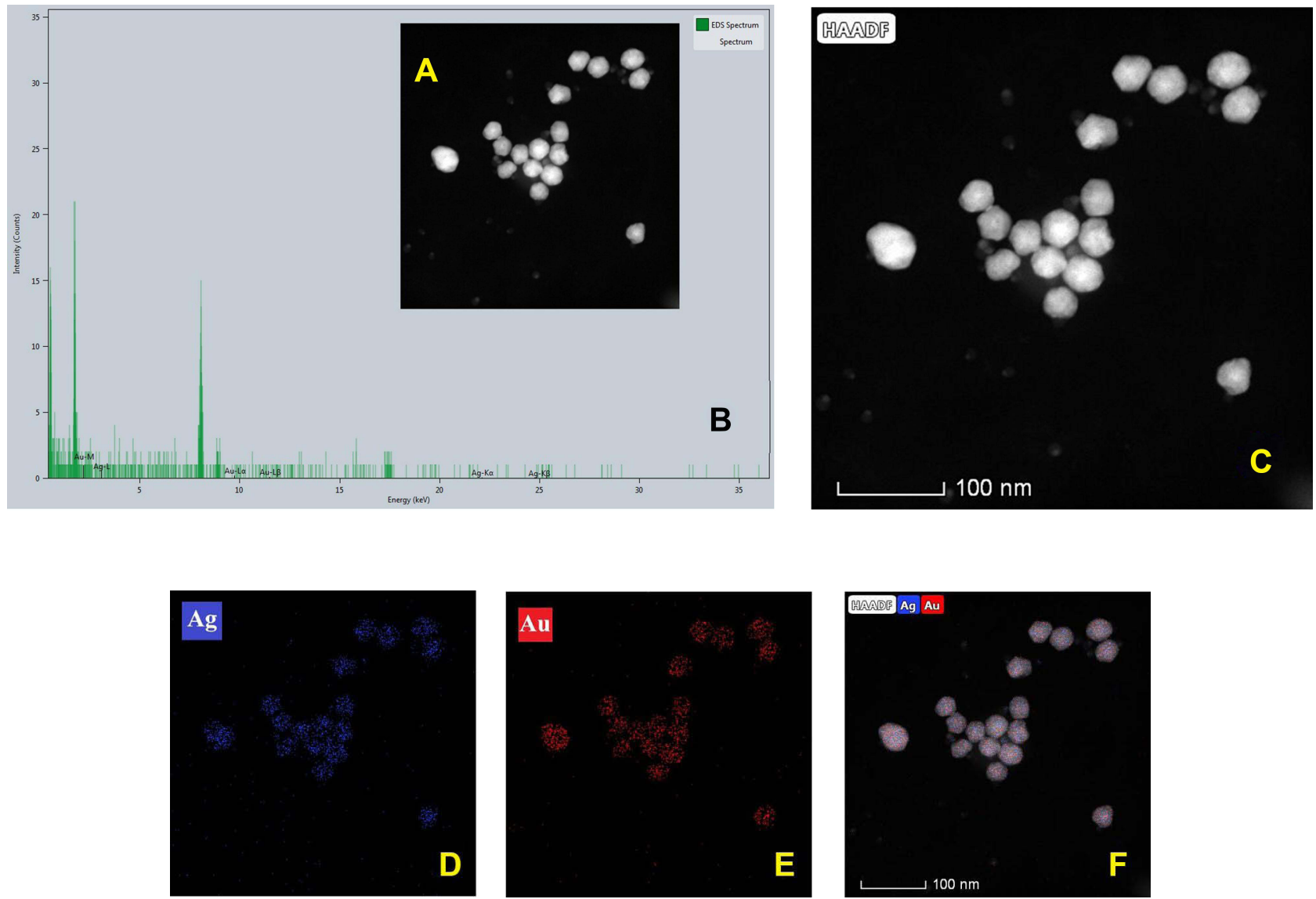

Figure 7 (A) HAADF-STEM image of the BNPs inserted in (B) EDX spectrum from a set of BNPs. (C-F) HAADF images showing mosaic of Au-Ag EDS elemental mapping showing the intermix of both elements within the set of nanoparticles. 
illustrates the alloy-type of the synthesized $\mathrm{Au}-\mathrm{Ag}$ particles. EDX confirmed distribution of both metals in BNPs and no individual monometallic particles were seen. The EDS spectrum of bimetallic $\mathrm{Au}-\mathrm{Ag}$ NPs is shown in Figure $7 \mathrm{~B}$ with an insert in Figure 7A of HAADF-STEM of BNPs. The spectrum BNPs show peaks corresponding to $\mathrm{Ag} 3.00 \mathrm{eV}$ and $3.15 \mathrm{eV}$, while the peak at 2.0, 9.5, and $11.5 \mathrm{keV}$, corresponds to $\mathrm{Au}{ }^{49}$

\section{Concentration Analysis of BNPs by ICPMS}

Furthermore, inductively coupled plasma mass spectroscopy (ICPMS) was used to quantify the gold and silver content in BNPs. The amount of silver and gold present in solution of BNPs (in ppb) 131 and 205, respectively, was measured using ICP-MS against a standard solution, as shown in the Supporting Information (Table T1- Calibration of ICPMS and T2- Working parameter of ICPMS).

\section{Raman Spectroscopy of PEG 600 and BNPs}

Figure 8A shows vibrational modes characteristic of peaks of PEG 600 at 471, 557, 883, 1013, 1240, 1283,
1479, 2563, 2700, 2878, 2940 and $3458 \mathrm{~cm}^{-1}$. Also, Figure $8 \mathrm{~B}$ shows the Raman spectrum of PEG 600 in the region of $400-600 \mathrm{~cm}^{-1}$. The Raman peaks are shifted by up to $\left(15-20 \mathrm{~cm}^{-1}\right)$ from the corresponding ones in the Raman spectrum of the PEG alone; such a region shown here is 480 to $500 \mathrm{~cm}^{-1}$ and $502-520 \mathrm{~cm}^{-1}$, suggesting the PEGylation of BNPs shown in Figure 8C. This phenomenon is common in SERS; if ligand, molecules or drugs chemisorb to the surface of nanoparticles, they experience an uprise and shift in signal at reduced concentrations. In a similar study, pharmaceutical excipient of the Raman spectrum of the AgNPs colloid vibrational modes characteristic to SDS showed $20 \mathrm{~cm}^{-1}$ Raman shift. ${ }^{50}$ PEG at metal surface of BNPs experiences probably increased in the oscillator strength and orientation of molecule. ${ }^{51}$ It is demonstrated that controlled aggregation can produce a significant increase in the SERS response from silver nanoparticles. Dimer nanoparticles of BNPs and also presence of silver play a role in hot spot formation. Also, to add low zeta potential of $-5.6 \mathrm{mV}$ approximately may lead to formation of dimer configuration during characterization, as seen in TEM images. ${ }^{52}$ High performance SERS of nanoparticles indicate $\mathrm{Au}-\mathrm{Ag}$ bimetallic superstructures. The combined effects between two
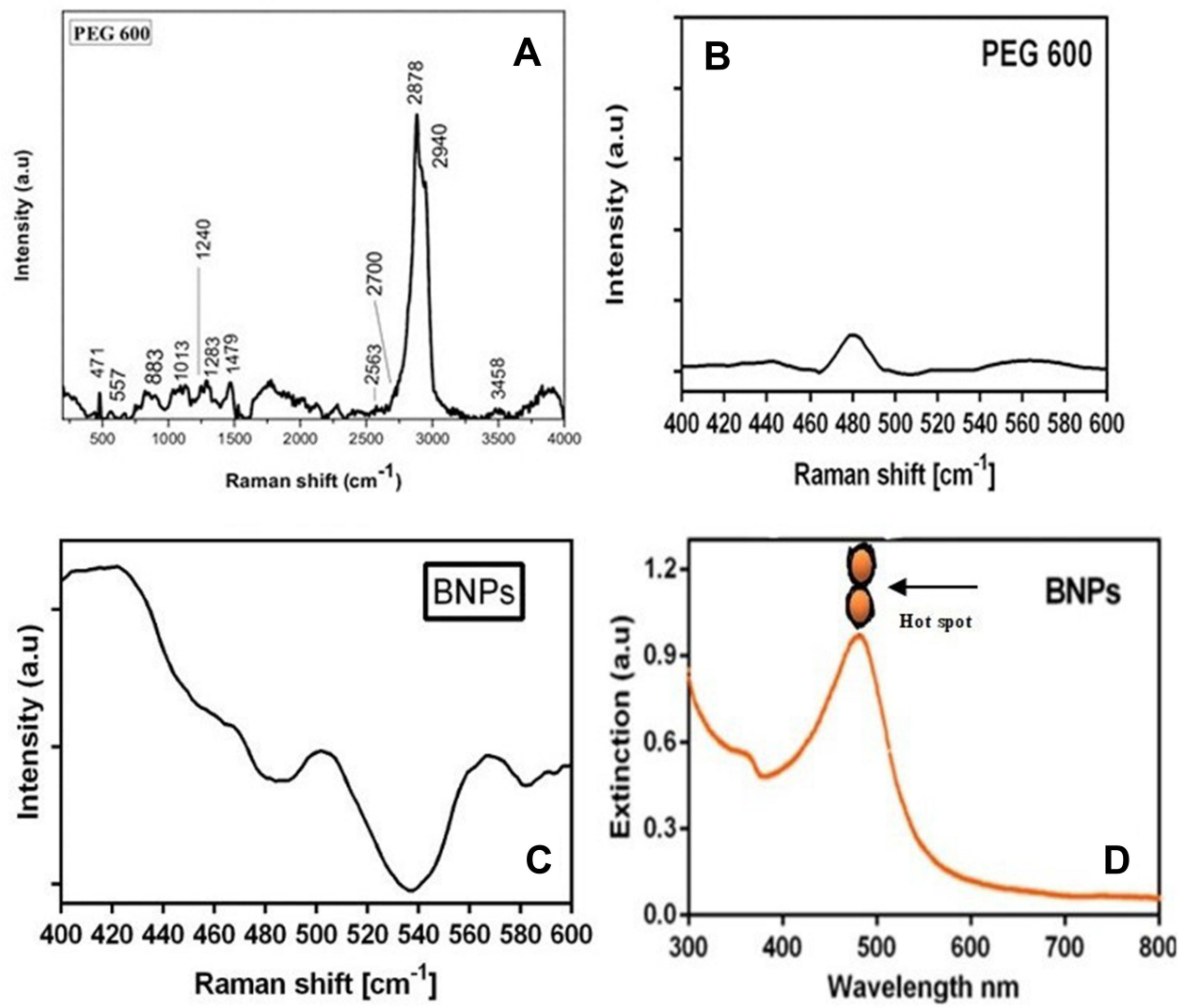

Figure 8 (A and B) Raman spectra collected from PEG 600 and (C) BNPs and (D) UV-vis spectrum depicting hotspot dimer formation. 
noble metals and rich "hotspots" shown in Figure 8D (dimer formation shown on the UV-vis spectrum) create a superstructure that enhances SERS detection by Ag shell and makes $\mathrm{Au}-\mathrm{Ag}$ superstructures highly attractive. ${ }^{53}$

\section{'H NMR Spectroscopy of PEG 600 and BNPs}

The spectrum in Figure 9A confirms the structure of PEG 600; ${ }^{1} \mathrm{H}$ NMR (400 MHz, DMSO) $\delta 4.55 \mathrm{ppm}$ is a hydroxy triplet, $\delta(3.30-3.47 \mathrm{ppm})$ is attributed to methine protons signals of PEG and considered as PEG backbone $^{25}$ and DMSO $\mathrm{d}_{6} \delta 2.55 \quad \mathrm{ppm}^{54,55}$ The synthesized BNPs spectrum in Figure 9B shows DMSO $\mathrm{d}_{6} \delta 2.55 \mathrm{ppm}$ and 3.35-3.45 ppm methine protons of polyethylene glycol units but the characteristic signal hydroxyl peak $\delta 4.55 \mathrm{ppm}$ has disappeared. The possible explanation is that ${ }^{-} \mathrm{OH}$ has taken part in the synthesis and entrapped inside the PEG capsule or corona of nanoparticles. It is also evident that the zeta potential is less negative in BNPs as hydroxyl-end groups ${ }^{-} \mathrm{OH}$ consumption has occurred, leading to entrapped and few at surface, rather weak positive $\mathrm{CH}_{3}{ }^{+}$methyl group surround the NPs along with less ${ }^{-} \mathrm{OH}$ groups owing to less negative zeta potential of $-5.6 \mathrm{mV}^{56}$
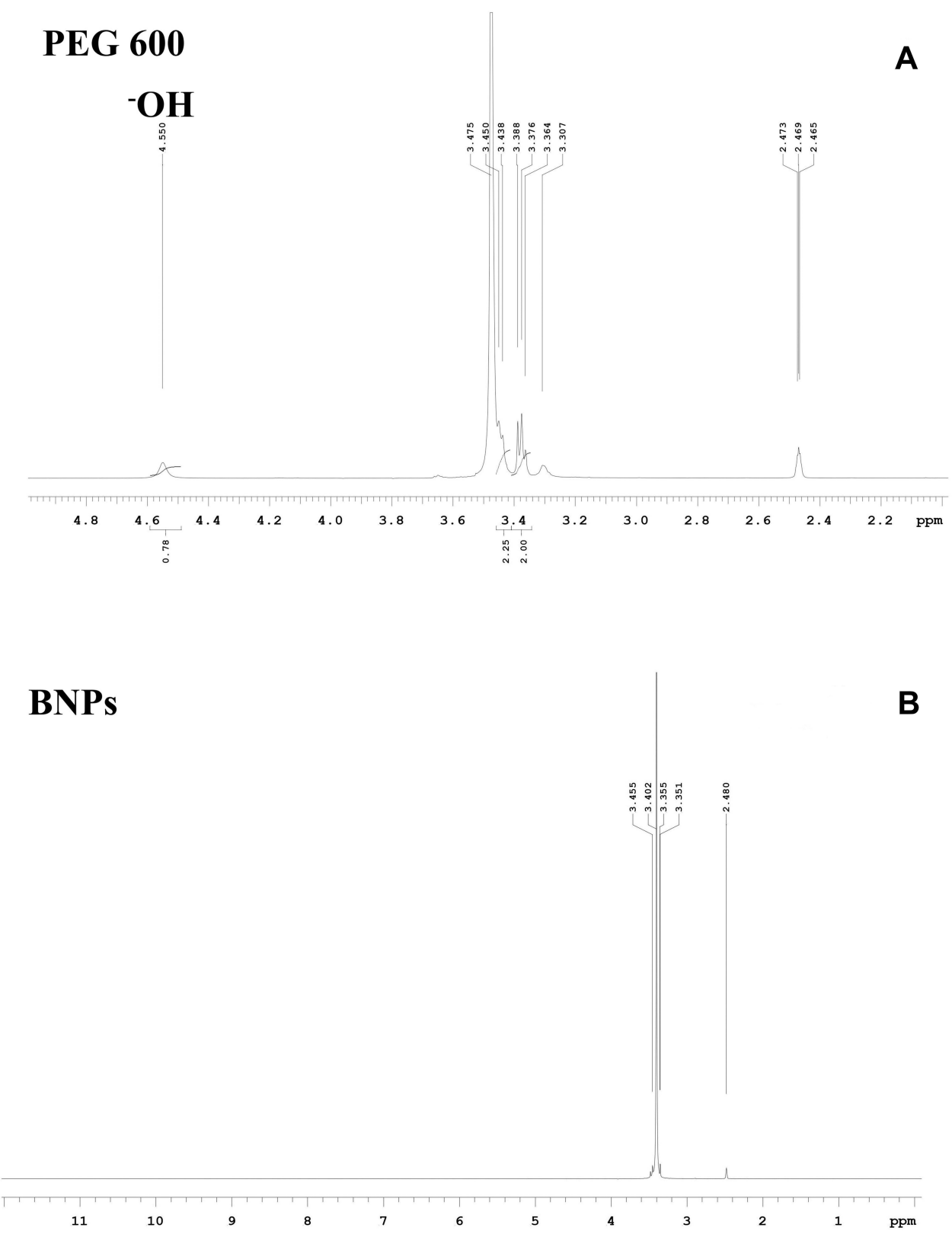

Figure 9 'H NMR (A) PEG 600 (B) PEG-coated BNPs in DMSO-d6 at 400 MHz. 


\section{Cytotoxicity Assay of BNPs and Irradiated KB Cells}

$\mathrm{KB}$ cells were treated with six low concentration doses of 50nm BNPs without X-ray treatment for $24 \mathrm{~h}$ and cell viability was determined using MTT assay. No appreciable difference was seen between the total cell number of the control cells except that 0.34 and $0.17 \mu \mathrm{g} / \mathrm{mL}$ BNPs showed slight toxicity (Figure 10A). The cytotoxic potential of NPs depends on material or elements used or arranged. The shape of nanoparticles plays a crucial role in determining nano toxicity. The toxic potency of silver is dependent on the shape, where nanotriangle exhibit more damage compared to nanospherical silver NPs. Nanomaterials have large surface area resulting in higher toxic and reaction potential. The uptake of NPs by cells is dependent on factors such as size, shape, zeta-potential, nature of the capping agent, vehicle and coating. After entering cells, NPs are transported to the cytoplasm and nucleus. Following are the mechanisms that caused toxicity, which include cell cycle deregulation, the decrease of mitochondrial function, reactive oxygen species (ROS) generation, release of lactate dehydrogenase (LDH), and apoptotic genes triggered leading to formation of chromosome aberration, formation of micronuclei and DNA damage. BNPs, by altering the nano surface, can increase their efficiency in cancer therapy by lowering adverse effects on normal cells. ${ }^{21}$ BNPs showed relative toxic potential to $\mathrm{KB}$ cell line, although low dose concentrations were used. Accumulation of BNPs into cells could be aided by the hydrophilic PEG surface coating leading to pinocytosis by the cells; these negatively charged BNPs may permeate more rapidly across the cell membrane layer due to electrostatic repulsion from the negative charge. ${ }^{57}$ Once BNPs enters cells, it splits and release of Ag occurs, resulting in greater toxicity. Usually, solutions containing Ag-NPs, zero-valent silver $\left(\mathrm{Ag}^{\circ}\right)$ sometimes occur with forms of ionic Ag, which is due to partial reduction of precursors or oxidation of silver NPs to release $\mathrm{Ag}+$ ions. When comparing $\mathrm{Ag}^{0}$ to cationic silver $(\mathrm{Ag}+)$, the potential toxicity is seen in the ionic form of silver. Toxicological potency varies as a function of oxidation state and also dissolution characteristics of NPs. ${ }^{58}$ Many types of monometallic gold-based radiosensitizer with shape and surface modifications have shown a range of SER values and gold nanorods having value of 1.21 which is least compared to 2.30 of TAT-Au NPs. . It is also noteworthy that Bismuth-based NPs have shown SER from 1.06 to 1.53 . Finally, tungsten and tantalum passed NPs showing values of 1.22 and 1.33 , respectively. ${ }^{74,75}$ In silver-doped lanthanum manganite nanoparticles, as the silver component increased so higher intracellular reactive oxygen species (ROS) and radiotoxicity was observed as silver ions increased in the structure of the NPs. ${ }^{59}$ When KB cells were exposed to X-ray irradiation alone, a dosedependent cell viability was seen, relative to the control cells; see Figure 10B. Dose-dependent results were seen along with significant differences between the treated with different dose groups ( 2 vs $4 \mathrm{~Gy}, \mathrm{p}=0.2$; 2 vs $8 \mathrm{~Gy}, \mathrm{p}=0.04$; 4 vs $8 \mathrm{~Gy}, \mathrm{p}=0.46$ ). It was seen that the lowest dose required to have cytotoxicity was $4 \mathrm{~Gy}$. Furthermore,
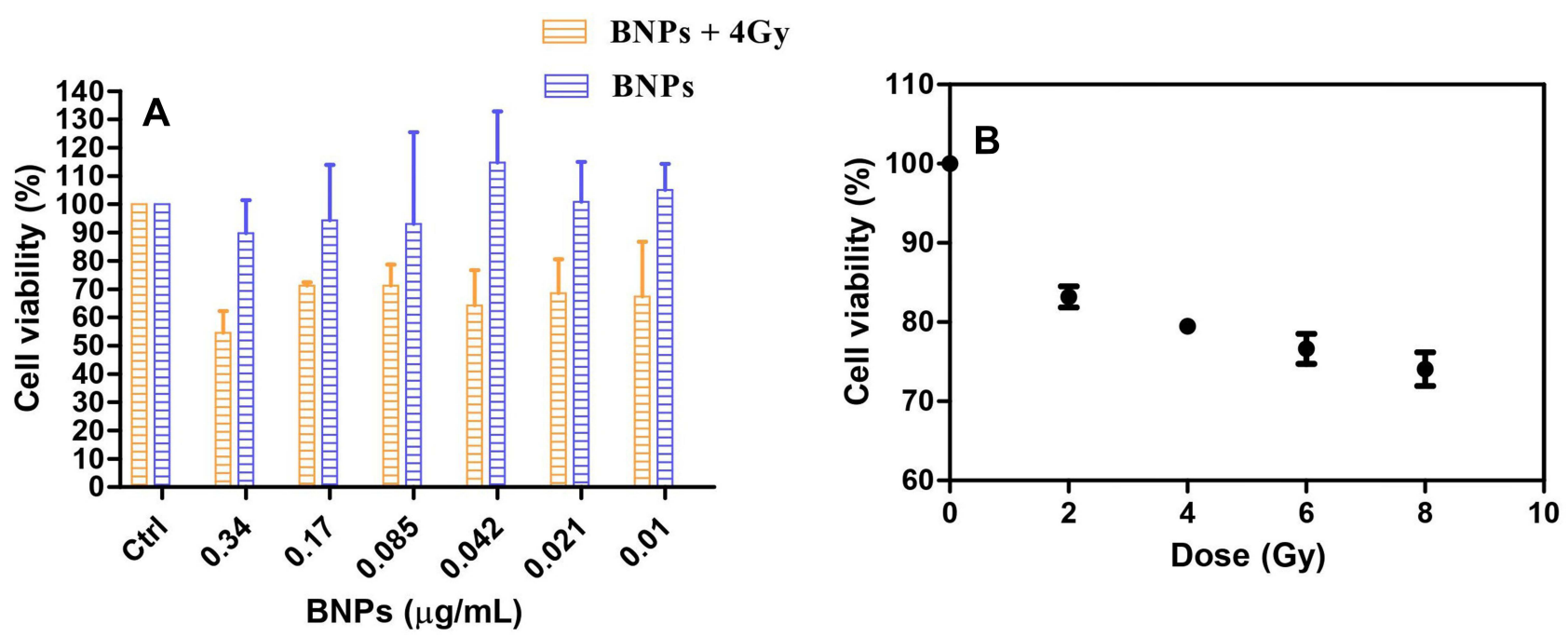

Figure 10 (A) Cell viability assay using MTT after $24 \mathrm{~h}$ treatment of KB cells with various doses of 50nm BNPs and KB cells treated with various doses of $50 \mathrm{~nm}$ BNPs for 24 $h$ and exposed to $4 G y \times$ Ray dose $(B) K B$ cells treated with various doses of $X$-ray $(0,2,4,6$, and 8 Gy). Cell viability is expressed as $\%$ cell viability \pm SD between ( $n=3)$. 
previous studies showed that molecular blockade could enhance radiosensitivity when irradiated with 4Gy. Hence, the X-ray dose of 4Gy was selected for subsequent experiments. ${ }^{60}$ When cancer cells are exposed to ionizing radiation, the nucleus is damaged, typical of double-strand breakage, leading to the traditional "programmed cell death" known as apoptosis. The main mechanisms by which cells lose their viability is by radiation damage via intrinsic mechanisms, such as DNA damage sensors, stress response, cytokines, and ROS/RNS initiated signaling pathways, or extrinsic mechanisms, such as up-regulation of death receptors. Radiation-induced apoptosis can be mediated by the up-regulation and engagement of death receptors such as TRAIL, Fas ligand (FasL), and programmed death-ligand-1 (PDL1) or their corresponding receptors. 2.5-10 Gy ionizing radiation induced dosedependent apoptosis increased expression of p53, Fas, TRAIL, TRAIL-R2, and down-regulation of Survivin antiapoptotic protein in stem cells of neuroblastoma $6 \mathrm{~h}$ after RT. $^{61}$

\section{In vitro Radiosensitization}

$\mathrm{KB}$ cells were treated with the same six low concentrations doses of 50nm BNPs and incubated for $24 \mathrm{~h}$. After $24 \mathrm{~h}$ of incubation, a 96-well plate was washed with PBS then fresh media was added followed by irradiation with 4Gy X-rays. Only internalized nanoparticles could contribute to radiosensitization. The combination of $0.34 \mu \mathrm{g} / \mathrm{mL}$ BNPs and 4Gy irradiation significantly reduced the total cell viable number compared with 4Gy irradiation alone (Figure 10A). For radiosensitization to be effective, the BNPs must undergo pinocytosis. ${ }^{62}$ Higher concentration implies a greater number of particles internalized compared to lower doses. This in vitro study result suggests that BNPs are effective radiosensitizers even at smaller doses. Glucose-coated gold nanoparticles have shown a 1.5 2.0-fold enhancement in growth inhibition when compared to GNPs alone; although it was demonstrated that GNPs can significantly enhance radiosensitivity in prostate cancer treatment. ${ }^{63}$ The BNPs contain gold as one of the constituents. The rationale for its radiosensitivity is that it was shown that viability of cells with internalized 50-nm gold nanoparticles was reduced for all irradiations due to the high cellular uptake of the gold nanoparticles compared to nanoparticles of other sizes. ${ }^{11}$ Also, it is shown that $50 \mathrm{~nm}$ bimetallic $\mathrm{Au}-\mathrm{Ag}$ NPs and Ag NPs are good radiosensitizers. ${ }^{12}$ As mentioned above, the $\mathrm{Ag}^{+}$ion leaks are lethal. All these factors enhance the radiosensitivity of the BNPs. The synergism is by virtue of the presence of high $\mathrm{Z}$ element gold, metal ion releasing silver as $\mathrm{Ag}^{+}$ions, the size of nanoparticles $50 \mathrm{~nm}$ and finally clinically significant dose of 4Gy. Sensitization enhancement ratio (SER) for each BNP dose is calculated as the ratio between the cell viability of the 4Gy exposed KB cells. BNPs have shown a 1.5 1.7-fold enhancement in growth inhibition when compared to $4 \mathrm{~Gy}$ alone. After demonstrating the radiosensitization potential of BNPs under $4 \mathrm{~Gy}$ X-ray radiation, we next examined nuclear damage of $\mathrm{KB}$ cells under the same dosage and X-ray irradiation.

\section{Nuclear Damage by Evaluation Using Hoechst}

To evaluate the nuclear damage of $\mathrm{KB}$ cells treated with BNPs $0.34 \mu \mathrm{g} / \mathrm{mL}$, 4Gy X-ray radiation and synergy of (BNPs $0.34 \mu \mathrm{g} / \mathrm{mL}+4$ Gy X-ray) radiosensitization were analyzed. Here, the positive control $\mathrm{H}_{2} \mathrm{O}_{2}$ used was $50 \mu \mathrm{M}$ / $\mathrm{mL}$. KB cells which received only media were kept as controls for comparison. Apoptosis is determined by the presence of apoptotic bodies or chromatin condensation (ie, condensed and fragmented nuclei). The characteristic feature of mitotic catastrophe is the presence of nuclei which has two or more distinct lobes and micronuclei. Radiation-induced apoptosis is considered to be one of the main mechanism of cell death following exposure to radiation. ${ }^{64}$ Another study showed that mitotic catastrophe is considered a major mode of ionizing radiation induced cell death that is distinct from other mechanisms of clonogenic cell death widely known in the field of radiation biology. Also, apoptosis and mitotic catastrophe may overlap to some extent. ${ }^{36,65}$ As shown in Figure 11, the untreated control KB cells had normal nuclei and no other gross changes of cancer cell nuclei were observed and cells treated with BNPs showed mild apoptosis, KB cells radiation dose of 4Gy, $6 \mathrm{MV}$ (without BNPs) had a more destructive effect on fragmented nuclei and chromatin condensed nuclei in comparison to untreated control cells. The highest cell nuclei damage was observed in BNPs treated cells that received 4Gy radiation in comparison to positive control without radiation dose. Therefore, in this nuclear damage (apoptotic) study, it was concluded that BNPs could increase the efficacy of radiotherapy on $\mathrm{KB}$ cells and could effectively prevent and inhibit the KB cell growth. The percentages of all the doses are shown in Figure 12. 

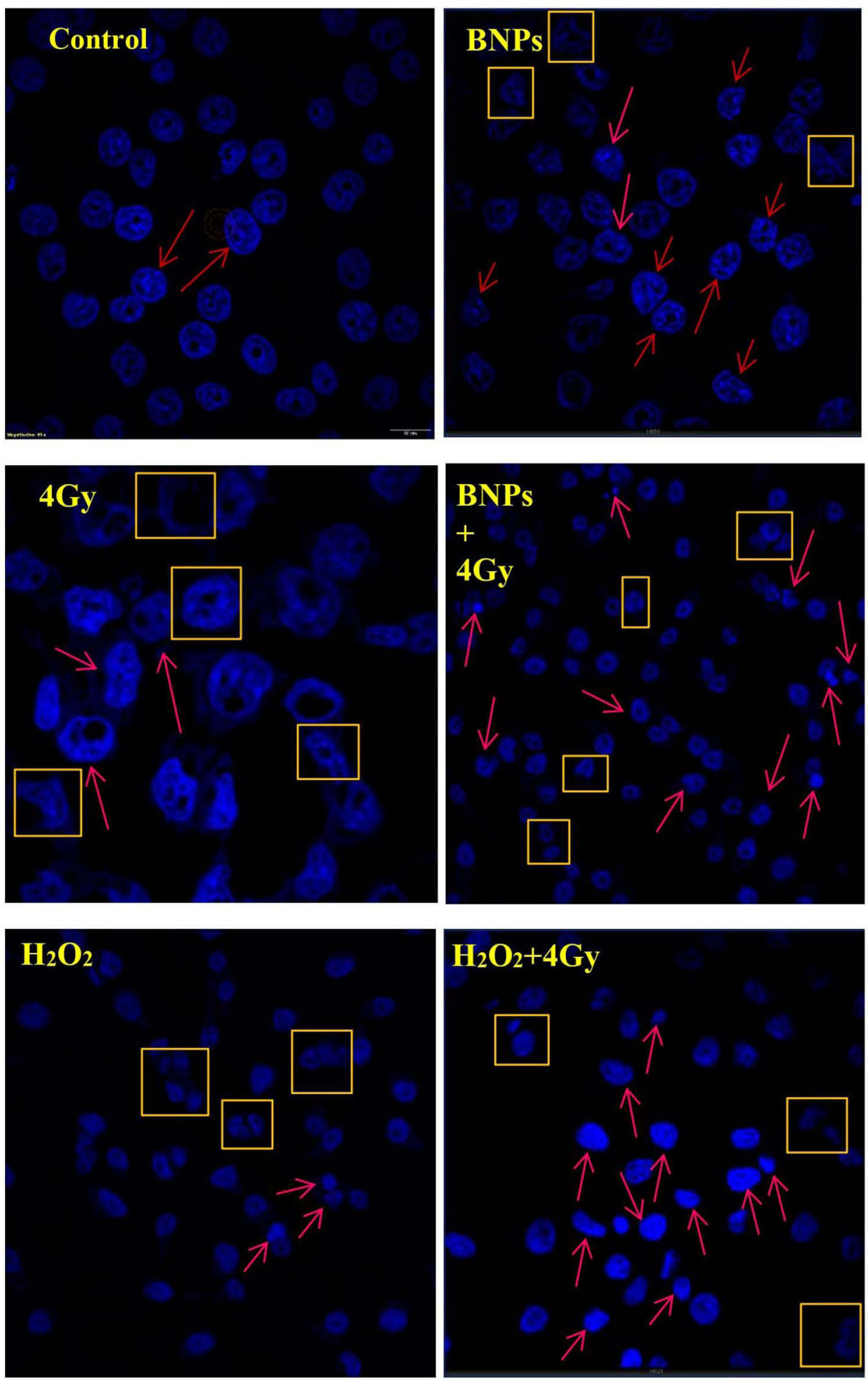

Figure II Confocal microscopic images of Hoechst-stained nuclei of cells treated with BNPs and X-rays. KB cells were irradiated with 4Gy X-rays and positive control $\mathrm{H}_{2} \mathrm{O}_{2}$ used was $50 \mu \mathrm{M} / \mathrm{mL}$. After $24 \mathrm{~h}$, the cells were fixed and stained with Hoechst. Imaging of nuclei was done at magnification of 20X and 60X lens. Arrows: apoptosis; boxes: mitotic catastrophe. Scale bar $=60 \mu \mathrm{m}$ 


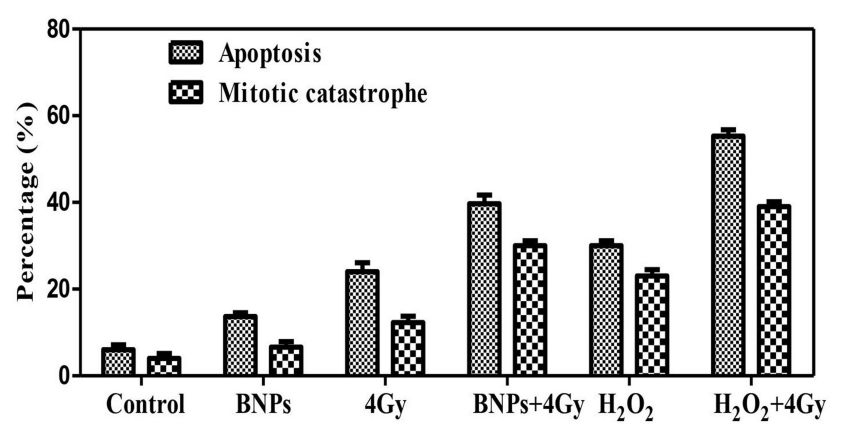

Figure 12 Quantified data for apoptosis, mitotic catastrophe of nuclei in KB cells treated with BNPs and $4 \mathrm{~Gy} X$-rays. $\mathrm{KB}$ cells were irradiated with dose $4 \mathrm{~Gy} \mathrm{X}$-rays and positive control $\mathrm{H}_{2} \mathrm{O}_{2}$ used was $50 \mu \mathrm{M} / \mathrm{mL}$. After $24 \mathrm{~h}$, the cells were fixed and stained with Hoechst. Imaging of nuclei was done at magnification of 20X and $60 \mathrm{X}$ lens. A total of 350 nuclei from random fields were evaluated for apoptosis and mitotic catastrophe $(n=3)$.

\section{CT Scan Phantom Model to Evaluate BNPs}

To evaluate capacity of the BNPs as CT nano contrast agents, samples were imaged using a clinical CT scanner at a tube voltage of $120 \mathrm{kVp}$ for a scan time of 3.0s. X-ray absorption studies of the BNPs have been carried out along with Omnipaque, which is routinely used to enhace the CT contrast.. Figure 13A depicts the phantom model images obtained for Milli Q, 1x PBS, BNPs with $0.6 \mathrm{mg} / \mathrm{mL}$, Omnipaque $5 \mathrm{mg} / \mathrm{mL}$ and $10 \mathrm{mg} / \mathrm{mL}$. Hounsfield Unit (HU) values were calculated from selected regions of interest (ROIs) for individual samples. Figure 13B shows that Milli $\mathrm{Q}$ and 1X PBS have no contrasting capacity; $0.6 \mathrm{mg} / \mathrm{mL}$ BNPs measured $38 \mathrm{HU}$ whereas X-ray absorption of $5 \mathrm{mg} /$ $\mathrm{mL}$ and $10 \mathrm{mg} / \mathrm{mL}$ Iodine in Omnipaque showed 120 and 220
HU, respectively. Although iodinated aromatic complexes are clinically injected into patients, they lack the ideal characteristic feature owing to low X-ray attenuations when high $\mathrm{kVp}$ CT parameters used. Relatively large doses of Omnipaque are administered to obtain optimal image quality. ${ }^{66}$ Higher HU value of BNPs seen through the concentration was low and was mainly due to the additive and synergistic effect of high X-ray attenuation coefficient of Au and Ag. Synthesized concentration was less compared to iodine-based contrast agent. This corresponds to an X-ray attenuation capacity of BNPs which is nearly 4 times higher than that of the iodine-based contrast agent, which could be attributed to the presence of electron dense nanogold and nanosilver particles in the BNPs. Gold has a higher atomic number and electron density (79 and $19.32 \mathrm{~g} / \mathrm{cm}^{3}$, respectively) in comparison to those of iodine (53 and $4.9 \mathrm{~g} / \mathrm{cm}^{3}$, respectively), implying this effect. It has already been shown that bare nano Au gave a CT signal intensity of $354 \mathrm{HU}$ for a concentration of $5 \mathrm{mg} / \mathrm{mL}$, which is nearly 2 -fold higher in comparison to the hybrid sample at its highest concentration of NPs. ${ }^{67,68}$ Silver NPs can be used as a potential alternative to iodine in dual-energy (DE) X-ray breast imaging. Silver performed better when compared to iodine-based contrast agents; silver contrast agent would be more beneficial than iodine, even when used in the clinic without altering of imaging system or protocol. ${ }^{69}$ PEGylation can significantly enhance the quality of imaging for nanomaterials; it is also seen that lengthening of $t^{1} / 2$ by up to 200 min can improve
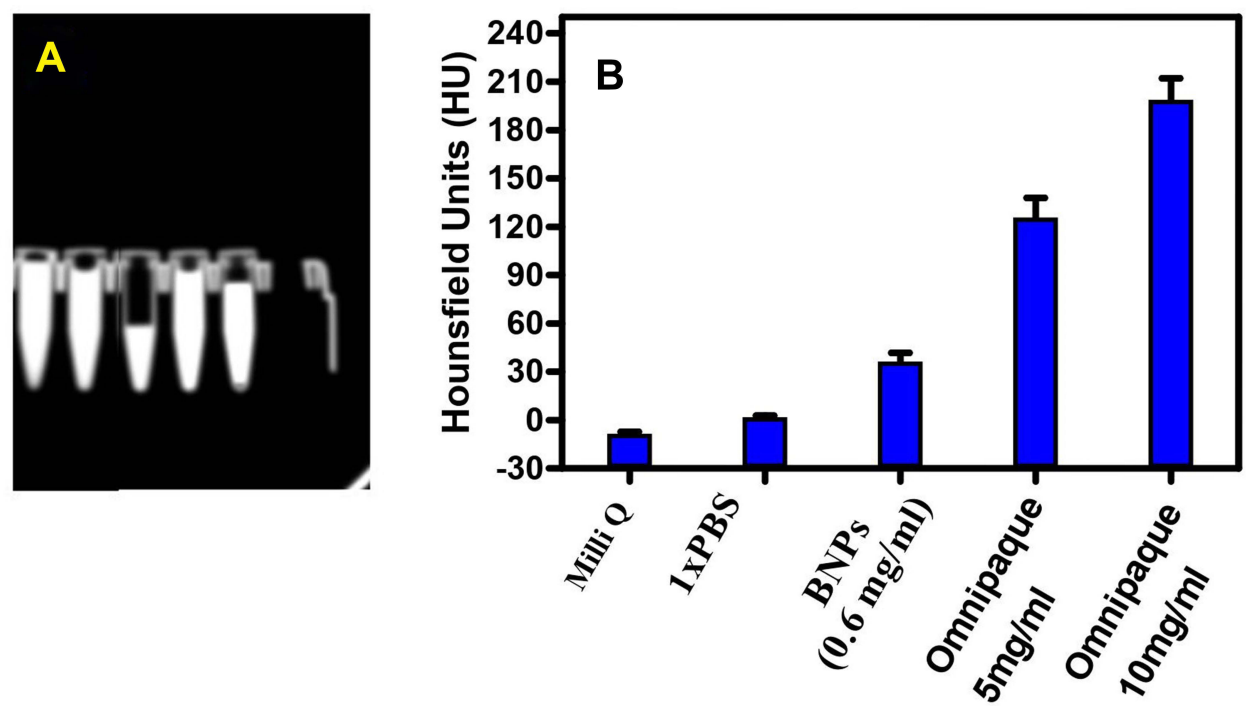

Figure 13 (A) CT images and (B) HU values of Milli Q, IX PBS, BNP 0.6mg/mL, Omnipaque $5 \mathrm{mg} / \mathrm{mL}$ and Omnipaque $10 \mathrm{mg} / \mathrm{mL}(\mathrm{n}=3)$. 


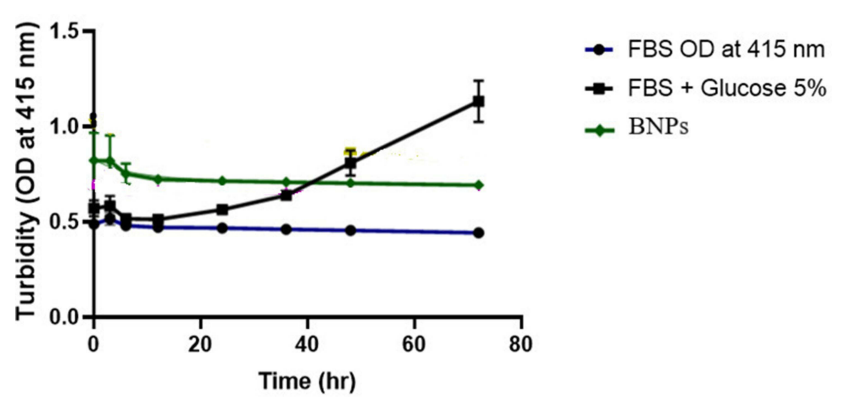

Figure 14 The stability of BNPs in fetal bovine serum. Negative control: $5 \%$ glucose was used.

image quality by dextran coating of SPIO and ultrasmall SPIO (USPIO) ${ }^{70}$

\section{Stability Assay of BNPs}

The objective of synthesizing BNPs is to use them in biological environments. To evaluate the stability of BNPs, FBS was used as a biological medium and the turbidity assay was performed by measuring the turbidity changes of BNP suspension in FBS. No significant difference in turbidity of BNPs and control suspensions was detected over the different incubation times as the turbidity changes in both suspensions were similar after $72 \mathrm{~h}$ of incubation (Figure 14). No serum protein interaction was seen or any aggregation. Any unnecessary interaction of BNPs and serum proteins in media could lead to agglomeration and the loss of treatment efficacy and efficiency. The aforementioned data show that the synthesized BNPs will exhibit excellent bioavailability in clinical scenarios. The negative control FBS combined with $5 \%$ glucose showed increase in OD reading at $415 \mathrm{~nm}$, a possible explanation for which is the exponential bacterial growth.

\section{Conclusion}

This study is the first of its kind to report successful one pot synthesis of PEGylated Bimetallic Au-Ag NPs using PEG 600. An orange-brownish well-dispersed colloidal BNPs PEG-capped nanoconstruct is both stable and more active with homogenous size distribution, with average hydrodynamic size being $\sim 50 \pm 5 \mathrm{~nm}$, and having a negative charge with zeta potential around $-5 \mathrm{mV}$. Electron microscopy reveals its near spherical morphology, monodisperse uniform diameter and dimension of $35 \mathrm{~nm}$. HAADF-STEM and elemental mapping studies showed the constituent metals where $\mathrm{Au}$ and $\mathrm{Ag}$ intermixed as a nanoalloy. ${ }^{1} \mathrm{H}$ NMR spectroscopy shows extended involvement of ${ }^{-} \mathrm{OH}$ in synthesis. When BNPs are exposed to oral cancer cells, they efficiently enter cells into the cytoplasm and nuclear periphery, leading to enhancement of radiation effect as demonstrated by in vitro radiosensitization with enhancement ratios of $\sim 1.5-1.7$. In conclusion, the current study confirms the radiosensitization effect of BNPs at 4Gy X-ray irradiation in (oral cancer) KB cells. Hoechst-stained nuclei imaging shows the strong apoptotic effect of internalized BNPs causing irreversible DNA damage. BNPs exhibit comparatively higher CT contrast ability compared to clinically used agent Omnipaque. Also, the BNPs are stable without agglomeration in a biological environment having optimum bioavailability. Synergism of constituent materials is a great boost for potential application of nanoalloy materials. ${ }^{71}$ Further research is required to validate the radiosensitizing effect on large tumors in in vivo studies to also evaluate the molecular mechanism by mRNA expression. Lastly, nano toxicological studies and biodistribution would help in to know more about BNPs' nanotherapeutic potential. The results obtained in this study are promising and we are currently working on BNPs loaded with Doxorubicin, an enhanced nanomedicine for combined therapeutic chemoradiation strategy against oral cancers.

\section{Acknowledgments}

This work will be incorporated in a PhD thesis: "Gold NPs Based Radiation Sensitizers and Drug Delivery System“. Also, one of the authors, Shameer Ahmed B, would like to extend his gratitude to BITS Pilani KK Birla Goa Campus, Goa, for the provision of an institutional fellowship for his PhD tenure. All the authors would like to thank the University of Mysore for DLS and Raman Spectroscopy, IIT (Indian Institutes of Technology) Delhi for ICPMS, Centre for Nano Science and Engineering (CeNSE)- IISc (Indian Institute of Science), Bangalore for HRTEM, HAADF-STEM, EDX. Manipal Hospital, Goa for LINAC Irradiation and CT Scanning facilities and Prof. Vinod K. Aswal, Solid State Physics Division, Bhabha Atomic Research Centre, Trombay, Mumbai for the design, measurements and analysis of SAXS and SANS. Lastly, we thank Dr. Varsha. K. Pavithran, Rajah Muthiah Dental College and Hospital, Annamalai University, for assisting in statistical analysis of this research article.

\section{Author Contributions}

All authors made a significant contribution to the work reported, whether that is in the conception, study design, execution, acquisition of data, analysis and interpretation, or in all these areas; took part in drafting, revising or 
critically reviewing the article; gave final approval of the version to be published; have agreed on the journal to which the article has been submitted; and agree to be accountable for all aspects of the work.

\section{Disclosure}

This study will form a chapter in the thesis of Mr. Shameer Ahmed, to be uploaded in 2022 to the Birla Institute of Technology and Science repository. The authors declare that they have no competing interests.

\section{References}

1. Tshering Vogel DW, Zbaeren P, Thoeny HC. Cancer of the oral cavity and oropharynx. Cancer Imaging. 2010;10(1):62-72. doi:10.1102/ 1470-7330.2010.0008

2. Ketabat F, Pundir M, Mohabatpour F, et al. Controlled drug delivery systems for oral cancer treatment-current status and future perspectives. Pharmaceutics. 2019;11(7):302. doi:10.3390/ pharmaceutics 11070302

3. Vanetti E, Clivio A, Nicolini G, et al. Volumetric modulated arc radiotherapy for carcinomas of the oro-pharynx, hypo-pharynx and larynx: a treatment planning comparison with fixed field IMRT Radiother Oncol. 2009;92(1):111-117. doi:10.1016/j.radonc.20 08.12.008

4. Brun E, Sicard-Roselli C. Actual questions raised by nanoparticle radiosensitization. Radiat Phys Chem Oxf Engl. 2016;128:134-142. doi:10.1016/j.radphyschem.2016.05.024

5. Wang H, Mu X, He H, Zhang X-D. Cancer radiosensitizers. Trends Pharmacol Sci. 2018;39(1):24-48. doi:10.1016/j.tips.2017.11.003

6. Zhang X-D, Luo Z, Chen J, et al. Ultrasmall Au(10-12)(SG)(10-12) nanomolecules for high tumor specificity and cancer radiotherapy. Adv Mater. 2014;26(26):4565-4568. doi:10.1002/adma.201400866

7. Liu P, Jin H, Guo Z, et al. Silver nanoparticles outperform gold nanoparticles in radiosensitizing U251 cells in vitro and in an intracranial mouse model of glioma. Int $J$ Nanomedicine. 2016;11:5003-5014. doi:10.2147/IJN.S115473

8. Zhao J, Liu P, Ma J, et al. Enhancement of radiosensitization by silver nanoparticles functionalized with polyethylene glycol and aptamer As1411 for glioma irradiation therapy. Int $J$ Nanomedicine. 2019;14:9483-9496. doi:10.2147/IJN.S224160

9. Maggiorella L, Barouch G, Devaux C, et al. Nanoscale radiotherapy with hafnium oxide nanoparticles. Future Oncol. 2012;8 (9):1167-1181. doi:10.2217/fon.12.96

10. Huo S, Ma H, Huang K, et al. Superior penetration and retention behavior of $50 \mathrm{~nm}$ gold nanoparticles in tumors. Cancer Res. 2013;73 (1):319-330. doi:10.1158/0008-5472.CAN-12-2071

11. Chithrani DB, Jelveh S, Jalali F, et al. Gold nanoparticles as radiation sensitizers in cancer therapy. Radiat Res. 2010;173(6):719-728. doi:10.1667/RR1984.1

12. Fathy MM. Biosynthesis of silver nanoparticles using thymoquinone and evaluation of their radio-sensitizing activity. Bionanoscience. 2020;10(1):260-266. doi:10.1007/s12668-019-00702-3

13. Le Tourneau C, Calugaru V, Thariat JO, et al. Hafnium oxide nanoparticles as a promising emergent treatment for head and neck cancer. Int J Radiat Oncol Biol Phys. 2018;100(5):1377. doi:10.1016/j. ijrobp.2017.12.180

14. Sreekumaran Nair A, Suryanarayanan V, Pradeep T, Thomas J, Anija M, Philip R. AuxAgy@ZrO2 core-shell nanoparticles: synthesis, characterization, reactivity and optical limiting. Mater Sci Eng B Solid State Mater Adv Technol. 2005;117(2):173-182. doi:10.1016/ j.mseb.2004.11.010
15. Shim K, Lee W-C, Heo Y-U, et al. Rationally designed bimetallic Au@Pt nanoparticles for glucose oxidation. Sci Rep. 2019;9(1):894. doi:10.1038/s41598-018-36759-5

16. Cui L, Her S, Borst GR, Bristow RG, Jaffray DA, Allen C. Radiosensitization by gold nanoparticles: will they ever make it to the clinic? Radiother Oncol. 2017;124(3):344-356. doi:10.1016/j. radonc.2017.07.007

17. Generalov R, Kuan WB, Chen W, Kristensen S, Juzenas P. Radiosensitizing effect of zinc oxide and silica nanocomposites on cancer cells. Colloids Surf B Biointerfaces. 2015;129:79-86. doi:10.1016/j.colsurfb.2015.03.026

18. Molina Higgins MC, Clifford DM, Rojas JV. Au@TiO2 nanocomposites synthesized by $\mathrm{X}$-ray radiolysis as potential radiosensitizers. Appl Surf Sci. 2018;427:702-710. doi:10.1016/j.apsusc.2017.08.094

19. Her S, Jaffray DA, Allen C. Gold nanoparticles for applications in cancer radiotherapy: mechanisms and recent advancements. $A d v$ Drug Deliv Rev. 2017;109:84-101. doi:10.1016/j.addr.2015.12.012

20. Zhang X-D, Wu D, Shen X, Liu P-X, Fan F-Y, Fan S-J. In vivo renal clearance, biodistribution, toxicity of gold nanoclusters. Biomaterials. 2012;33(18):4628-4638. doi:10.1016/j.biomaterials.2012.03.020

21. Botha TL, Elemike EE, Horn S, Onwudiwe DC, Giesy JP, Wepener V. Cytotoxicity of Ag, Au and Ag-Au bimetallic nanoparticles prepared using golden rod (Solidago canadensis) plant extract. Sci Rep. 2019;9(1):4169. doi:10.1038/s41598-019-40816-y

22. Lomelí-Marroquín D, Medina Cruz D, Nieto-Argüello A, et al. Starch-mediated synthesis of mono- and bimetallic silver/gold nanoparticles as antimicrobial and anticancer agents. Int J Nanomedicine. 2019;14:2171-2190. doi:10.2147/IJN.S192757

23. Mukha I, Vityuk N, Grodzyuk G, et al. Anticancer effect of Ag, Au, and $\mathrm{Ag} / \mathrm{Au}$ bimetallic nanoparticles prepared in the presence of tryptophan. J Nanosci Nanotechnol. 2017;17(12):8987-8994. doi:10.1166/jnn.2017.14106

24. Katifelis H, Lyberopoulou A, Mukha I, et al. Ag/Au bimetallic nanoparticles induce apoptosis in human cancer cell lines via P53, CASPASE-3 and BAX/BCL-2 pathways. Artif Cells Nanomed Biotechnol. 2018;46(sup3):S389-S398. doi:10.1080/21691401.20 18.1495645

25. Ritschel T, Lehmann K, Brunzel M, et al. Well-defined poly(ethylene glycol) polymers as non-conventional reactive tracers of colloidal transport in porous media. $J$ Colloid Interface Sci. 2021;584:592-601. doi:10.1016/j.jcis.2020.09.056

26. Gref R, Minamitake Y, Peracchia MT, Trubetskoy V, Torchilin V, Langer R. Biodegradable long-circulating polymeric nanospheres. Science. 1994;263(5153):1600-1603. doi:10.1126/science.8128245

27. Shkilnyy A, Soucé M, Dubois P, Warmont F, Saboungi M-L, Chourpa I. Poly(ethylene glycol)-stabilized silver nanoparticles for bioanalytical applications of SERS spectroscopy. Analyst. 2009;134 (9):1868-1872. doi:10.1039/b905694g

28. Suk JS, Xu Q, Kim N, Hanes J, Ensign LM. PEGylation as a strategy for improving nanoparticle-based drug and gene delivery. Adv Drug Deliv Rev. 2016;99(Pt A):28-51. doi:10.1016/j.addr.2015.09.012

29. Kwatra D, Venugopal A, Anant S. Nanoparticles in radiation therapy: a summary of various approaches to enhance radiosensitization in cancer. Transl Cancer Res. 2013;2(4). doi:10.3978/j.issn.2218-676X.2013.08.06

30. Wang M, Thanou M. Targeting nanoparticles to cancer. Pharmacol Res. 2010;62(2):90-99. doi:10.1016/j.phrs.2010.03.005

31. Zopes D, Hegemann C, Schläfer J, Tyrra W, Mathur S. Single-source precursors for alloyed gold-silver nanocrystals - a molecular metallurgy approach. Inorg Chem. 2015;54(8):3781-3787. doi:10.1021/ic502924s

32. Ristig S, Kozlova D, Meyer-Zaika W, Epple M. An easy synthesis of autofluorescent alloyed silver-gold nanoparticles. J Mater Chem B Mater Biol Med. 2014;2(45):7887-7895. doi:10.1039/c4tb01010h

33. Soulé S, Bulteau A-L, Faucher S, et al. Design and cellular fate of bioinspired Au-Ag nanoshells@hybrid silica nanoparticles. Langmuir. 2016;32(39):10073-10082. doi:10.1021/acs.langmuir.6b02810 
34. Naha PC, Lau KC, Hsu JC, et al. Gold silver alloy nanoparticles (GSAN): an imaging probe for breast cancer screening with dual-energy mammography or computed tomography. Nanoscale. 2016;8(28):13740-13754. doi:10.1039/c6nr02618d

35. Ahmed BS, Rao AG, Sankarshan BM, et al. Evaluation of gold, silver and silver-gold (bimetallic) nanoparticles as radiosensitizers for radiation therapy in cancer treatment. Canc Oncol Res. 2016;4 (3):42-51. doi:10.13189/cor.2016.040302

36. Kobayashi D, Shibata A, Oike T, Nakano T. One-step protocol for evaluation of the mode of radiation-induced clonogenic cell death by fluorescence microscopy. J Vis Exp. 2017;128. doi:10.3791/56338.

37. Li T, Shen X, Chen Y, et al. Polyetherimide-grafted $\mathrm{Fe}_{3} \mathrm{O}_{4} @ \mathrm{SiO}_{2}$ nanoparticles as theranostic agents for simultaneous VEGF siRNA delivery and magnetic resonance cell imaging. Int $J$ Nanomedicine. 2015;10:4279-4291. doi:10.2147/IJN.S85095

38. Sharma C, Ansari S, Ansari MS, Satsangee SP, Srivastava MM. Single-step green route synthesis of $\mathrm{Au} / \mathrm{Ag}$ bimetallic nanoparticles using clove buds extract: enhancement in antioxidant bio-efficacy and catalytic activity. Mater Sci Eng C Mater Biol Appl. 2020;116 (111153):111153. doi:10.1016/j.msec.2020.111153

39. Stiufiuc R, Iacovita C, Nicoara R, et al. One-step synthesis of PEGylated gold nanoparticles with tunable surface charge. J Nanomater. 2013;2013:1-7. doi:10.1155/2013/146031

40. Alam MJ, Tsuji M, Matsunaga M, Yamaguchi D. Shape changes in $\mathrm{Au}-\mathrm{Ag}$ bimetallic systems involving polygonal $\mathrm{Au}$ nanocrystals to spherical $\mathrm{Au} / \mathrm{Ag}$ alloy and excentered $\mathrm{Au}$ core $\mathrm{Ag} / \mathrm{Au}$ alloy shell particles under oil-bath heating. CrystEngComm. 2011;13 (8):2984-2993. doi:10.1039/c0ce00899k

41. Huang J, Li Q, Sun D, et al. Biosynthesis of silver and gold nanoparticles by novel sundriedCinnamomum camphora leaf. Nanotechnology. 2007;18(10):105104. doi:10.1088/0957-4484/18/10/105104

42. Laaksonen T, Ahonen P, Johans C, Kontturi K. Stability and electrostatics of mercaptoundecanoic acid-capped gold nanoparticles with varying counterion size. Chemphyschem. 2006;7(10):2143-2149. doi: $10.1002 /$ cphc. 200600307

43. Patsula V, Horák D, Kučka J, et al. Synthesis and modification of uniform PEG-neridronate-modified magnetic nanoparticles determines prolonged blood circulation and biodistribution in a mouse preclinical model. Sci Rep. 2019;9(1):10765. doi:10.1038/s41598019-47262-w

44. Zhang H, Okuni J, Toshima N. One-pot synthesis of Ag-Au bimetallic nanoparticles with Au shell and their high catalytic activity for aerobic glucose oxidation. J Colloid Interface Sci. 2011;354 (1):131-138. doi:10.1016/j.jcis.2010.10.036

45. Murugavelu M, Karthikeyan B. Synthesis, characterization of Ag-Au core-shell bimetal nanoparticles and its application for electrocatalytic oxidation/sensing of 1-methionine. Mater Sci Eng C Mater Biol Appl. 2017;70(Pt 1):656-664. doi:10.1016/j.msec.2016.09.046

46. Banerjee M, Sharma S, Chattopadhyay A, Ghosh SS. Enhanced antibacterial activity of bimetallic gold-silver core-shell nanoparticles at low silver concentration. Nanoscale. 2011;3(12):5120-5125. doi:10.1039/c1nr10703h

47. Vinod M, Gopchandran KG. Au, Ag and Au: Ag colloidal nanoparticles synthesized by pulsed laser ablation as SERS substrates. Prog Nat Sci. 2014;24(6):569-578. doi:10.1016/j.pnsc.2014.10.003

48. Berahim N, Basirun W, Leo B, Johan M. Synthesis of bimetallic gold-silver (Au-Ag) nanoparticles for the catalytic reduction of 4-nitrophenol to 4-aminophenol. Catalysts. 2018;8(10):412. doi:10.3390/catal 8100412

49. Guadagnini A, Agnoli S, Badocco D, et al. Facile synthesis by laser ablation in liquid of nonequilibrium cobalt-silver nanoparticles with magnetic and plasmonic properties. $J$ Colloid Interface Sci. 2021;585:267-275. doi:10.1016/j.jcis.2020.11.089

50. Pinzaru I, Coricovac D, Dehelean C, et al. Stable PEG-coated silver nanoparticles - a comprehensive toxicological profile. Food Chem Toxicol. 2018;111:546-556. doi:10.1016/j.fct.2017.11.051
51. Vodnik VV, Mojić M, Stamenović U, et al. Development of genistein-loaded gold nanoparticles and their antitumor potential against prostate cancer cell lines. Mater Sci Eng C Mater Biol Appl. 2021;124(112078):112078. doi:10.1016/j.msec.2021.112078

52. Tian F, Bonnier F, Casey A, Shanahan AE, Byrne HJ. Surface enhanced Raman scattering with gold nanoparticles: effect of particle shape. Anal Methods. 2014;6(22):9116-9123. doi:10.1039/ c4ay02112f

53. Dai L, Song L, Huang Y, et al. Bimetallic Au/Ag core-shell superstructures with tunable surface plasmon resonance in the near-infrared region and high performance surface-enhanced Raman scattering. Langmuir. 2017;33(22):5378-5384. doi:10.1021/acs.langmuir.7b00097

54. Dust JM, Fang ZH, Harris JM. Proton NMR characterization of poly (ethylene glycols) and derivatives. Macromolecules. 1990;23 (16):3742-3746. doi:10.1021/ma00218a005

55. Xu X, He Z, Lu S, Guo D, Yu J. Enhanced thermal and mechanical properties of lignin/polypropylene wood-plastic composite by using flexible segment-containing reactive compatibilizer. Macromol Res. 2014;22(10):1084-1089. doi:10.1007/s13233-014-2161-3

56. Meabe L, Sardon H, Mecerreyes D. Hydrolytically degradable poly (ethylene glycol) based polycarbonates by organocatalyzed condensation. Eur Polym J. 2017;95:737-745. doi:10.1016/j. eurpolymj.2017.06.046

57. Sharifi F, Jahangiri M, Nazir I, et al. Zeta potential changing nanoemulsions based on a simple zwitterion. J Colloid Interface Sci. 2021;585:126-137. doi:10.1016/j.jcis.2020.11.054

58. Xiu Z-M, Zhang Q-B, Puppala HL, Colvin VL, Alvarez PJJ. Negligible particle-specific antibacterial activity of silver nanoparticles. Nano Lett. 2012;12(8):4271-4275. doi:10.1021/ nl301934w

59. Khochaiche A, Westlake M, O'Keefe A, et al. First extensive study of silver-doped lanthanum manganite nanoparticles for inducing selective chemotherapy and radio-toxicity enhancement. Mater Sci Eng C Mater Biol Appl. 2021;123(111970):111970. doi:10.1016/j. msec.2021.111970

60. Teraoka S, Kakei Y, Akashi M, et al. Gold nanoparticles enhance $\mathrm{X}$-ray irradiation-induced apoptosis in head and neck squamous cell carcinoma in vitro. Biomed Rep. 2018;9(5):415-420. doi:10.3892/ br.2018.1142

61. McKelvey KJ, Hudson AL, Back M, Eade T, Diakos CI. Radiation, inflammation and the immune response in cancer. Mamm Genome. 2018;29(11-12):843-865. doi:10.1007/s00335-018-9777-0

62. Bhattarai SR, Derry PJ, Aziz K, et al. Gold nanotriangles: scale up and X-ray radiosensitization effects in mice. Nanoscale. 2017;9 (16):5085-5093. doi:10.1039/c6nr08172j

63. Zhang X, Xing JZ, Chen J, et al. Enhanced radiation sensitivity in prostate cancer by gold-nanoparticles. Clin Invest Med. 2008;31(3): E160-7. doi:10.25011/cim.v31i3.3473

64. Eriksson D, Stigbrand T. Radiation-induced cell death mechanisms. Tumour Biol. 2010;31(4):363-372. doi:10.1007/s13277-010-0042-8

65. Wouters BG. Cell death after irradiation: how, when and why cells die. In: Basic Clinical Radiobiology. CRC Press; 2018:21-31. doi:10.1201/9780429490606-3

66. Meenambal R, Kannan S. Design and structural investigations of Yb3 + substituted $\beta$-Ca3(PO4)2 contrast agents for bimodal NIR luminescence and X-ray CT imaging. Mater Sci Eng C Mater Biol Appl. 2018;91:817-823. doi:10.1016/j.msec.2018.06.032

67. Mishra SK, Kannan S. Doxorubicin-conjugated bimetallic silver-gadolinium nanoalloy for multimodal MRI-CT-optical imaging and pH-responsive drug release. ACS Biomater Sci Eng. 2017;3 (12):3607-3619. doi:10.1021/acsbiomaterials.7b00498

68. Narayanan S, Sathy BN, Mony U, Koyakutty M, Nair SV, Menon D. Biocompatible magnetite/gold nanohybrid contrast agents via green chemistry for MRI and CT bioimaging. ACS Appl Mater Interfaces. 2012;4(1):251-260. doi:10.1021/am201311c 
69. Karunamuni R, Tsourkas A, Maidment AD. Exploring silver as a contrast agent for contrast-enhanced dual-energy X-ray breast imaging. $\mathrm{Br} J$ Radiol. 2014;87(1041):20140081. doi:10.1259/ bjr.20140081

70. Jokerst JV, Lobovkina T, Zare RN, Gambhir SS. Nanoparticle PEGylation for imaging and therapy. Nanomedicine (Lond). 2011;6 (4):715-728. doi: $10.2217 / \mathrm{nnm} .11 .19$

71. Rachna RM, Shanker U. Synergistic effects of zinc oxide coupled copper hexacyanoferrate nanocomposite: robust visible-light driven dye degradation. $J$ Colloid Interface Sci. 2021;584:67-79. doi:10.1016/j.jcis.2020.09.079

72. Bindhu J, Anupama G. Radiosensitization: the new dogma in cancer treatment. Austral-Asian J Cancer. 2005;4(4):241-50. ISSN-09722556.

73. Xiong Z, Qin F, Huang P-S, Nettleship I, Lee J-K. Effect of synthesis techniques on crystallization and optical properties of Ag-cu bimetallic nanoparticles. JOM. 2016;68(4):1163-1168. doi:10.1007/ s11837-015-1757-1
74. Ma N, Fu-Gen W, Zhang X, et al. Shape-dependent radiosensitization effect of gold nanostructures in cancer radiotherapy: comparison of gold nanoparticles, nanospikes, and nanorods. ACS Appl Mater Interfaces. 2017;9(15):13037-13048. doi:10.1021/acsami.7b01112

75. Zhang X, Chen X, Jiang Y-W, et al. Glutathione-depleting gold nanoclusters for enhanced cancer radiotherapy through synergistic external and internal regulations. ACS Appl Mater Interfaces. 2018;10(13):10601-10606. doi:10.1021/acsami.8b00207

76. Ma N, Liu P, Nongyue H, Ning G, Fu-Gen W, Chen Z. Action of gold nanospikes-based nanoradiosensitizers: cellular internalization, radiotherapy, and autophagy. ACS Appl Mater Interfaces. 2017;9 (37):31526-31542. doi:10.1021/acsami.7b09599

77. Rawat L, Hegde H, Hoti SL, Nayak V. Piperlongumine induces ROS mediated cell death and synergizes paclitaxel in human intestinal cancer cells. Biomed Pharmacother. 2020;128:110243-110249. doi:10.1016/j.biopha.2020.110243
International Journal of Nanomedicine

\section{Publish your work in this journal}

The International Journal of Nanomedicine is an international, peerreviewed journal focusing on the application of nanotechnology in diagnostics, therapeutics, and drug delivery systems throughout the biomedical field. This journal is indexed on PubMed Central, MedLine, CAS, SciSearch ${ }^{\mathbb{2}}$, Current Contents ${ }^{\mathbb{R}} /$ Clinical Medicine,
Dovepress

Journal Citation Reports/Science Edition, EMBase, Scopus and the Elsevier Bibliographic databases. The manuscript management system is completely online and includes a very quick and fair peer-review system, which is all easy to use. Visit http://www.dovepress.com/ testimonials.php to read real quotes from published authors. 